\title{
Observed Atmospheric Responses to Global SST Variability Modes: A Unified Assessment Using GEFA*
}

\author{
NA WEN \\ Physical Oceanography Laboratory, and Ocean-Atmosphere Interaction and Climate Laboratory, \\ Ocean University of China, Qingdao, China
}

ZHENGYU LIU

Center for Climatic Research, Department of Atmospheric and Oceanic Sciences, University of Wisconsin-Madison, Madison, Wisconsin, and Physical Oceanography Laboratory, and Ocean-Atmosphere Interaction and Climate Laboratory, Ocean University of China, Qingdao, China

QINYU LIU

Physical Oceanography Laboratory, and Ocean-Atmosphere Interaction and Climate Laboratory, Ocean University of China, Qingdao, China

Claude Frankignoul

LOCEAN, Université Pierre et Marie Curie, Paris, France

(Manuscript received 13 January 2009, in final form 2 July 2009)

\begin{abstract}
The authors present a comprehensive assessment of the observed atmospheric response to SST variability modes in a unified approach using the Generalized Equilibrium Feedback Analysis (GEFA). This study confirms a dominant atmospheric response to the tropical SST variability associated with ENSO. A further analysis shows that the classical response to ENSO consists of two parts, one responding to the tropical Pacific ENSO mode and the other to the tropical Indian Ocean monopole (IOM) mode. The Pacific ENSO generates a significant baroclinic Rossby wave response locally over the tropical Pacific as well as equivalent barotropic wave train responses remotely into the extratropics. The IOM mode forces a strongly zonally symmetric response throughout the tropics and the extratropics. Furthermore, modest atmospheric responses to other oceanic modes were identified. For example, the North Pacific SST variability mode appears to generate an equivalent barotropic warm SST-ridge response locally over the Aleutian low with significant downstream influence on the North Atlantic Oscillation (NAO), whereas the North Atlantic tripole SST mode tends to force a local response on NAO. Finally, this pilot study serves as a demonstration of the potential utility of GEFA in identifying multiple surface feedbacks to the atmosphere in the observation.
\end{abstract}

\section{Introduction}

It has long been recognized from observations that the sea surface temperature (SST) variability associated with ENSO exerts a significant impact on global atmosphere (e.g., Bjerknes 1966, 1969; Trenberth et al. 1998).

* CCR Contribution Number 981.

Corresponding author address: Z. Liu, 1225 W. Dayton St., Madison, WI 53706.

E-mail: zliu3@wisc.edu
Recent observational studies further identified evidences of atmospheric responses to SST variability in other oceans, such as the North Atlantic (NA; e.g., Czaja and Frankignoul 2002), North Pacific (NP; e.g., Q. Liu et al. 2006; Frankignoul and Sennechael 2007) and the tropical Indian Ocean (TI; e.g., Saji et al. 1999; Lau et al. 2005, 2006; Yang et al. 2007). In spite of all these works, there has been no comprehensive assessment of the atmospheric response to global oceanic variability modes in the observation. Indeed, except for the response to ENSO, it has remained challenging in observations to isolate the atmospheric response to a specific oceanic variability 
mode, because the atmospheric response is usually forced by multiple concurrent SST forcings (e.g., Klein et al. 1999; Newman et al. 2003; Lau et al. 2006). One common practice has been to filter out the dominant external forcing, usually ENSO, with regression and then to assess the climate impact using the residual variability (e.g., Chiang and Vimont 2004; Q. Liu et al. 2006; Frankignoul and Sennechael 2007). This approach is effective only if there is a single dominant external forcing and this forcing is known a priori. In general, with complex interactions among multiple oceanic forcings, the simple residual approach is no longer effective. Alternatively, climate models have been used heavily to perform sensitivity experiments with a specified anomalous SST forcing (e.g., Alexander et al. 2002; Barsugli and Sardeshmukh 2002; Hoerling and Kumar 2003; Hoerling et al. 2004; Liu and $\mathrm{Wu}$ 2004). The modeling approach, albeit dynamically appealing, is subject to model biases. Even if the model is perfect, identifying the impacts of various oceanic forcings would require extensive ensemble sensitivity experiments.

Here, we present a comprehensive assessment of the observed atmospheric response to major global SST modes in a unified framework, using the recently developed multivariate method Generalized Equilibrium Feedback Analysis (GEFA) method (Liu et al. 2008, hereafter LWY08; Liu and Wen 2008, hereafter LW08). Global oceanic variability forcings are represented with regional SST EOF modes for two reasons. Physically, regional SST EOFs have been used as a convenient representation for SST variability modes and therefore are convenient for physical interpretations. Statistically, the use of the leading SST EOFs as the base for analysis improves the estimator and reduces the sampling error significantly (see LWY08; LW08).

GEFA provides a systematic approach to identify atmospheric responses to individual oceanic forcings in the observation by taking into account the interaction among the forcings (section 2). As a test, GEFA will be applied first to the atmospheric response to SST variability in the tropical-extratropical North Pacific (section 3). This Pacific study shows that GEFA can recover the robust global atmospheric response to ENSO consistent with previous studies. In addition, GEFA identified a modest atmospheric response to the North Pacific SST, with a significant downstream response on the North Atlantic Oscillation (NAO). The Pacific study is then expanded to include SST forcings of global oceans. The global assessment shows that a significant portion of the ENSO impact is caused indirectly by the tropical Indian Ocean SST variability (section 4). Finally, major findings are summarized and some further discussions on GEFA are presented (section 5). A comparison of GEFA with the traditional residual approach is also discussed in appendixes A and B. Overall, our results show that GEFA provides a comprehensive and effective method to identify and understand the atmospheric response to various oceanic forcings in the observation.

\section{Data and method}

\section{a. Data}

We will assess the response of the atmospheric geopotential height $(\mathrm{GPH})$ to the dominant SST variability modes using the National Centers for Environmental Prediction-National Center for Atmospheric Research (NCEP-NCAR) Global Reanalysis 1 (NCEP-1) data of 1958-2007 (available online at http://www.cdc.noaa.gov/ cdc/data.ncep.reanalysis.derived.html). Our results remain robust when the time duration is split into two sections: 1958-79 and 1980-2007. The anomaly data are derived at each grid point by removing first the seasonal cycle and then a third-order polynomial fit. The atmospheric response is assessed at $250 \mathrm{hPa}(\mathrm{Z} 250)$ and $850 \mathrm{hPa}$ (Z850). The SST forcing is derived from regional EOFs as follows: First, the global ocean north of $20^{\circ} \mathrm{S}$ is divided into non-overlapping subbasins: the tropical Pacific (TP; $\left.20^{\circ} \mathrm{S}-20^{\circ} \mathrm{N}, 120^{\circ} \mathrm{E}-60^{\circ} \mathrm{W}\right)$, TI $\left(20^{\circ} \mathrm{S}-20^{\circ} \mathrm{N}, 35^{\circ}-120^{\circ} \mathrm{E}\right)$, tropical Atlantic $\left(\mathrm{TA} ; 20^{\circ} \mathrm{S}-20^{\circ} \mathrm{N}, 65^{\circ} \mathrm{W}-15^{\circ} \mathrm{E}\right), \mathrm{NP}\left(20^{\circ}-\right.$ $\left.60^{\circ} \mathrm{N}, 120^{\circ} \mathrm{E}-60^{\circ} \mathrm{W}\right)$, and NA $\left(20^{\circ}-60^{\circ} \mathrm{N}, 100^{\circ} \mathrm{W}-20^{\circ} \mathrm{E}\right)$. Regional SST EOFs are then obtained for each subbasin. Figure 1 shows the first EOFs and their corresponding principle components (PCs) in the tropical Pacific (TP1), tropical Indian Ocean (TI1), tropical Atlantic Ocean (TA1), North Pacific (NP1) and North Atlantic (NA1) corresponding to the ENSO mode, Indian Ocean monopole (IOM) mode, tropical Atlantic Niño mode, North Pacific mode, and North Atlantic tripole mode, respectively. The leading modes of these regional EOFs in various subbasins are then combined into a grand set of EOF modes to represent the set of ocean forcing.

\section{b. GEFA: Feedback matrix, total matrix, and forcing matrix}

GEFA is a multivariate generalization of the univariate feedback assessment method of Frankignoul et al. (1998). For distinction, the univariate method will be called EFA. A full discussion of GEFA has been given in LWY08 and LW08. Here, GEFA will be described briefly in the context of our application. Without loss of generality, we consider the GPH response at a single point. Assume the GPH anomaly at month $t(t=1, \ldots, L)$ is $z(t)$ (in meters), and this variability consists of a stochastic variability associated with the internal atmospheric 
(a) TP1
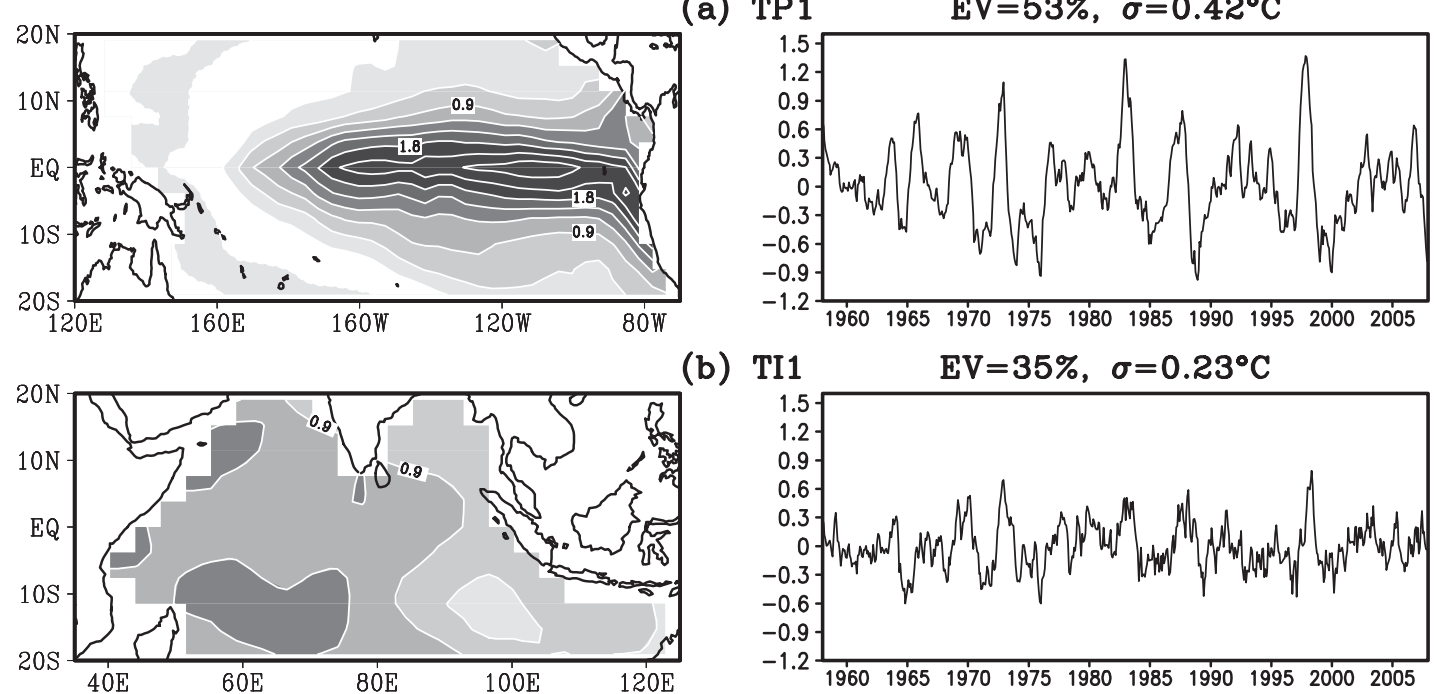

(b) $\mathrm{TI} 1$

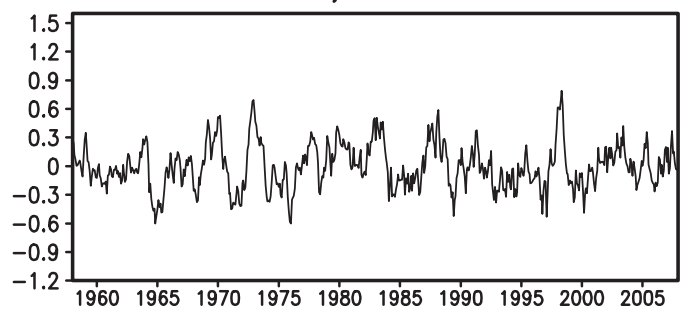

(c) TA1

$\mathrm{EV}=38 \%, \sigma=0.28^{\circ} \mathrm{C}$
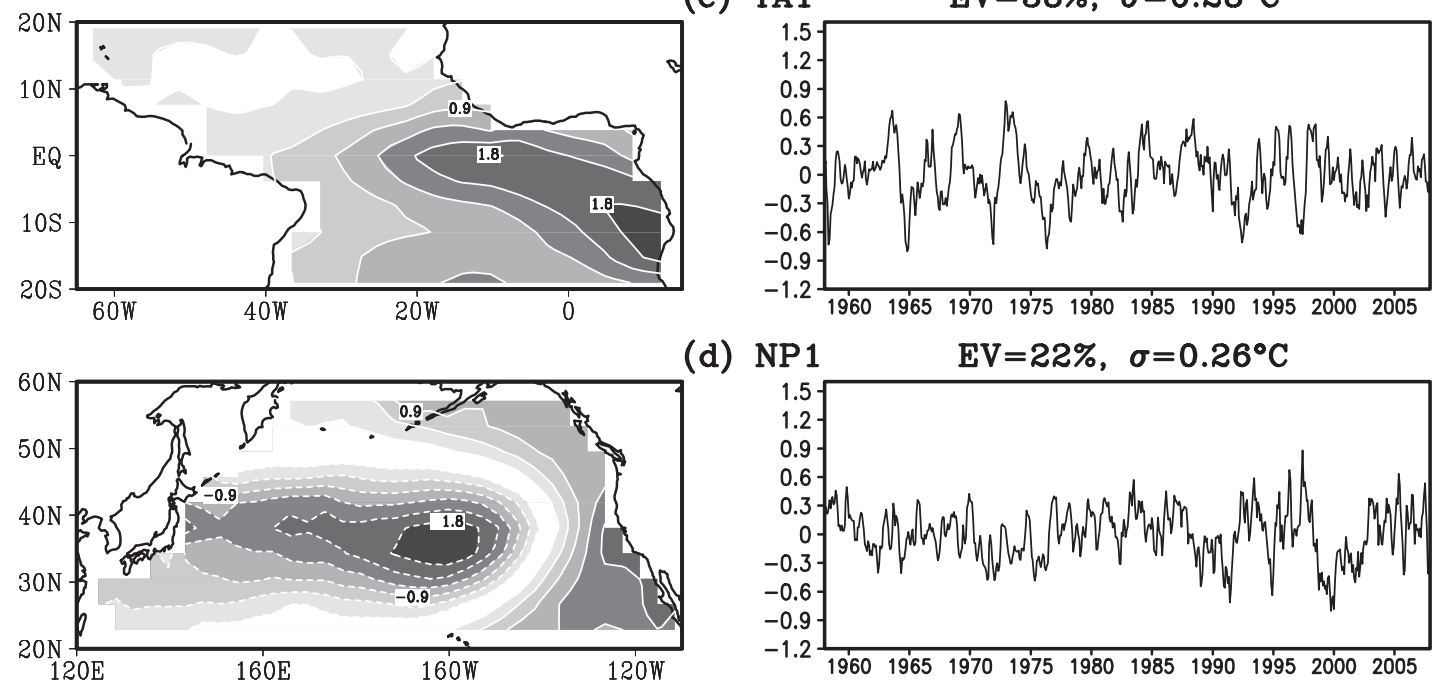

(d) NP1

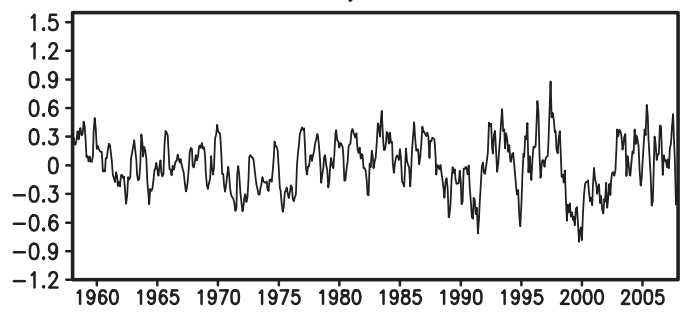

(e) NA1

$\mathrm{EV}=19 \%, \sigma=0.22^{\circ} \mathrm{C}$
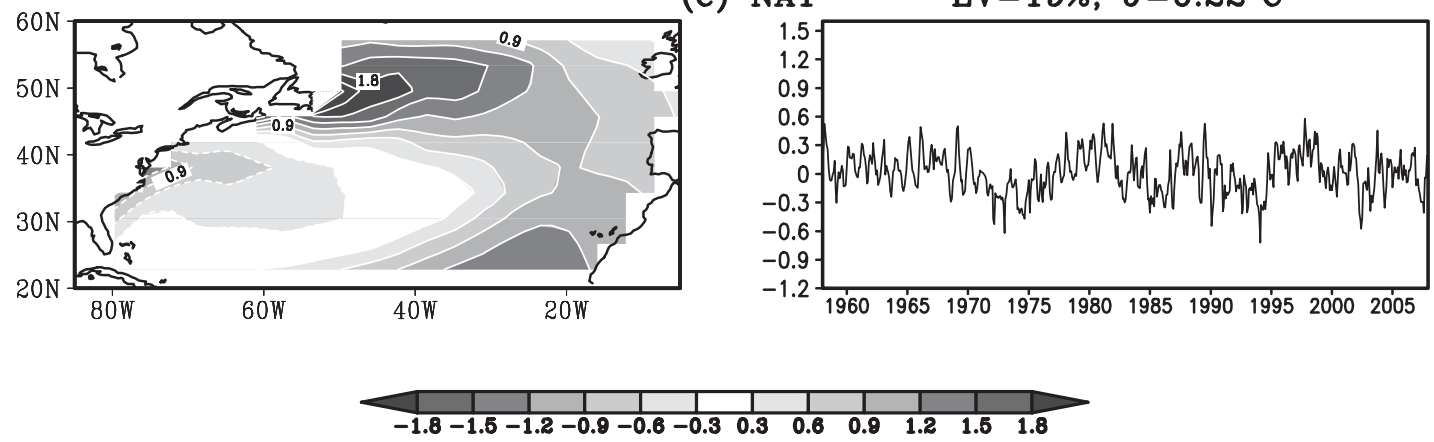

FIG. 1. The SST (left) EOF1 pattern and (right) PC for (a) TP, (b) TI, (c) TA, (d) NP, and (f) NA. Solid (dashed) contours for positive (negative) values [contour interval $(\mathrm{CI})=0.3^{\circ} \mathrm{C}$ ]. The magnitude of the spatial pattern is normalized with a standard deviation of $1^{\circ} \mathrm{C}$. 
variability $n(t)$ and a quasi-equilibrium response to a SST anomaly field of dimension $J$ (in ${ }^{\circ} \mathrm{C}$ ),

$$
\mathbf{y}(t)=\left[\begin{array}{c}
y_{1}(t) \\
\cdots \\
y_{J}(t)
\end{array}\right],
$$

such that

$$
z(t)=\mathbf{B y}(t)+n(t)
$$

where $\mathbf{B}=\left[b_{1} \ldots b_{J}\right]$ is the (response) Green's function, or the feedback (response) matrix, with $b_{j}\left(\right.$ in $\mathrm{m}^{\circ} \mathrm{C}^{-1}$ ) representing the sensitivity of the $\mathrm{GPH}$ response to $1^{\circ} \mathrm{C}$ of SST at the $j$ th point $y_{j}(t)$. The feedback matrix B can be derived after a right multiplication of the transpose of the SST of $\tau$ months earlier $\mathbf{y}^{\mathrm{T}}(t-\tau)$ as

$$
\mathbf{B}=\mathbf{C}_{z \mathbf{y}}(\tau) \mathbf{C}_{\mathbf{y y}}^{-1}(\tau)
$$

where the superscript $\mathrm{T}$ is for the transpose and $\mathbf{C}_{\mathbf{u v}}(\tau)=$ $\sum_{t=1}^{L} \mathbf{u}(t) \mathbf{v}^{\mathrm{T}}(t-\tau) / L$ is a lagged covariance matrix. The key to (2.2) is $\mathbf{C}_{n \mathbf{y}}(\tau)=0$ for $\tau$ longer than the persistence time of $n$. The lag $\tau$ is usually chosen to be $1-2$ months, longer than the time scales of the dominant internal atmospheric variability (Frankignoul et al. 1998). In general, $\tau$ should be longer than both the atmospheric response time and the persistence time of the atmospheric internal variability such that the equilibrium response (2.1) and $\mathbf{C}_{n \mathbf{v}}(\tau)=0$ are largely valid. An optimal $\tau$ should also be as short as possible to achieve a better condition on the matrix $\mathbf{C}_{\mathbf{y y}}(\tau)$ and in turn a reduced sampling error (Z. Liu et al. 2006).

The GEFA response can be shown to be related to a corresponding EFA response as (LWY08; LW08)

$$
\mathbf{A}=\mathbf{B M} \quad \text { or } \quad a_{j}=\sum_{i=1}^{J} b_{i} m_{i j} .
$$

Here, $\mathbf{A}=\left[a_{1} \ldots a_{J}\right]$ is the so-called total (response) matrix. Here,

$$
a_{j} \equiv \frac{C_{z y_{j}}(\tau)}{C_{y_{j} y_{j}}(\tau)}
$$

(in $\mathrm{m}^{\circ} \mathrm{C}^{-1}$ ) represents the atmospheric response to $j$ th SST estimated using the univarite EFA, as if the response was forced entirely by the $j$ th SST. In parallel to the GEFA response, this total response is called the EFA response. The EFA response erroneously attributes to the forcing of the $j$ th SST forcing as the response to all other SST forcings that are correlated with the $j$ th SST forcing. The difference between the GEFA and EFA responses, however, is helpful for our understanding of the interactions of SST modes and their responses. The attribution of different forcing on the EFA response in $\mathbf{A}$ can be given by a forcing matrix $\mathbf{M}=\left[m_{i j}\right](i, j=1, \ldots, J)$, where

$$
m_{i j} \equiv \frac{C_{y_{i} y_{j}}(\tau)}{C_{y_{j} y_{j}}(\tau)}
$$

which reflects the covariance among various forcing. The term $m_{i j}$ represents the weight of the contribution of the $i$ th SST forcing onto the total atmospheric response to the $j$ th SST forcing or simply the "contribution weight" of the $i$ th forcing on the $j$ th forcing. ${ }^{1}$ Relation (2.3a) can be interpreted as follows: the total (EFA) atmospheric response to the $j$ th SST forcing $a_{j}$ is the sum of the contributions from all the SST forcings, with each contribution being the GEFA response $b_{i}$ weighted by $m_{i j}$. Here, $\mathbf{M}$ is a nondimensional square matrix with the diagonal elements as 1 . The total EFA response to the $j$ th forcing would be the same as the corresponding GEFA response $\left(a_{j}=b_{j}\right)$ if $m_{i j}=0$ for $i \neq j$; this occurs when other forcings are either small or uncorrelated with the $j$ th forcing. Notice that both $\mathbf{A}$ and $\mathbf{M}$ are obtained using EFA instead of GEFA, and they are independent of the SST forcing points used in GEFA. As such, $\mathbf{A}$ and $\mathbf{M}$ are also not contaminated by the sampling errors associated with the covariance among the forcings; therefore, they are subject to less sampling error than B (for more details, see LWY08; LW08).

\section{c. GEFA in EOF space}

One effective approach to reducing the sampling error for the feedback matrix $\mathbf{B}$ associated with the covariance across the forcing field is to perform GEFA in a truncated SST EOF space (LWY08; LW08). For our application here, the use of regional SST EOFs as forcing bases are especially advantageous, because they provide a natural representation for SST variability forcings, as discussed earlier. Assume, for the time being, that the SST variability is represented by the EOFs in a single subbasin. Using the leading $\hat{J}$ SST EOFs, the synthetic SST variability can be reconstructed as

$$
\hat{\mathbf{y}}(t)=\sum_{j=1}^{\hat{J}} \mathbf{e}_{j} p_{j}(t), \quad t=1, \ldots, L,
$$

\footnotetext{
${ }^{1}$ The term $m_{i j}$ is not the coefficient. Instead, it depends on the correlation as much as autocorrelation and variance ratio as $m_{i j}=\operatorname{cor}\left\langle y_{i}(t) y_{j}(t-\tau)\right\rangle \times\left[1 / \operatorname{cor}\left\langle y_{j}(t) y_{j}(t-\tau)\right\rangle\right] \times\left[\sigma\left(y_{i}\right) / \sigma\left(y_{j}\right)\right]$.
} 
where $\left\{\mathbf{e}_{i}\right\}(j=1, \ldots, J)$ form a set of spatial base for SST, such as the EOF. ${ }^{2}$ Here, we will use $\mathbf{e}_{j}$ as the $j$ th EOF of a unit magnitude (standard deviation). Because the EOFs are now spatially orthogonal to each other, the projection time series can be derived simply as

$$
p_{j}(t)=\mathbf{e}_{j}^{T} \mathbf{y}(t)
$$

or the PC. The atmospheric variability (2.1) in terms of the leading SST PCs,

$$
\mathbf{p}(t)=\left[\begin{array}{c}
p_{1}(t) \\
\cdots \\
p_{\hat{J}}(t)
\end{array}\right],
$$

can be approximated as

$$
z(t)=\mathbf{B} \hat{\mathbf{y}}(t)+n(t)=\tilde{\mathbf{B}} \mathbf{p}(t)+n(t),
$$

where $\tilde{\mathbf{B}}=\left[\mathbf{B e}_{1} \ldots \mathbf{B e}_{\hat{J}}\right] \equiv\left[\tilde{b}_{1} \ldots \tilde{b}_{\hat{J}}\right]$ is the feedback matrix in the EOF space and can be derived as

$$
\tilde{\mathbf{B}}=\mathbf{C}_{z \mathbf{p}}(\tau) \mathbf{C}_{\mathbf{p p}}^{-1}(\tau)
$$

Now, with proper truncations, the singularity of $\mathbf{C}_{\mathbf{p p}}(\tau)$ and in turn the sampling error of $\mathbf{B}$ can be reduced significantly. Here, $\tilde{b}_{j}\left(\right.$ in $\mathrm{m}^{\circ} \mathrm{C}^{-1}$ ) can be interpreted as the response sensitivity of $z$ to $j$ th mode $\mathbf{e}_{j}$. Because each SST mode has the same magnitude, this response sensitivity can be compared among each other to evaluate the forcing efficiency of each SST mode. For the observed SST variability, the response magnitude to each SST mode can be further derived by a multiplication of the standard deviation of the PC as

$$
\tilde{b}_{j} \times \sigma\left[p_{j}(t)\right]
$$

This response magnitude can also be obtained if the EOF expansion (2.4) is done such that the PC, instead of the EOF, is normalized. In contrast to the response sensitivity (2.7) that represents the intrinsic atmospheric

\footnotetext{
${ }^{2}$ In general, spatial orthogonality is unnecessary for the SST base. The SST spatial base $\left\{\mathbf{e}_{i}\right\}$ can be any set of base of $\mathrm{J}$ base vectors as long as they are not degenerated: that is, the base matrix $\left[\mathbf{e}_{1}, \ldots \mathbf{e}_{J}\right]$ invertible. Indeed, rewrite Eq. (2.4) for the full variability in the matrix form as $[\mathbf{y}(1), \ldots \mathbf{y}(L)]=\left[\mathbf{e}_{1}, \ldots \mathbf{e}_{J}\right]\left[\mathbf{p}_{1}, \ldots \mathbf{p}_{J}\right]$, where $\mathbf{p}_{j}=\left[p_{j}(1), \ldots p_{j}(L)\right]$ is the time coefficient series (in row vector) on $\mathbf{e}_{j}$, and $\mathbf{p}_{j}$ can be determined uniquely as the $j$ th row of $\left[\mathbf{e}_{1}, \ldots \mathbf{e}_{J}\right]^{-1}[\mathbf{y}(1), \ldots \mathbf{y}(L)]$. In the special case of orthogonal bases, $\left[\mathbf{e}_{1}^{T}, \ldots \mathbf{e}_{J}^{T}\right]=\left[\mathbf{e}_{1}, \ldots \mathbf{e}_{J}\right]^{-1}$, the time series is simply the projection on $\mathbf{e}_{j}$ as $\mathbf{p}_{j}=e_{j}^{T}[\mathbf{y}(1), \ldots \mathbf{y}(L)]$ or (2.5).
}

response to a unit magnitude of the SST mode, the response magnitude (2.7) takes into account the SST magnitude. Finally, the operation from (2.4) to (2.6) and (2.7) only requires the orthogonality of the spatial patterns, rather than the time series, of the SST modes, and it can also be performed similarly on a base of SST modes consisting of multiple sets of regional EOFs, as used later. This follows, because the SST variability in different (nonoverlapping) ocean basins is spatially orthogonal.

\section{Atmospheric response to tropical-extratropical North Pacific SST}

\section{a. Response to tropical Pacific SST}

We start by assessing the atmospheric response to SST variability in the tropical-North Pacific domain. This exercise serves as a confirmation test to see if GEFA can recover the classical atmospheric response to ENSO in the presence of additional SST forcings in the tropical and North Pacific. Furthermore, this exercise serves as an exploratory study, searching for atmospheric responses to North Pacific SST.

As a standard case, we first use three regional SST EOFs in the tropical Pacific and North Pacific each to form a combined set of six EOFs (with the magnitude of the PCs shown in Table 1). The first three modes in the tropical Pacific, TP1, TP2, and TP3, account for 53\%, $13 \%$, and $5 \%$ of the variance, respectively, with TP1 being dominated by a warm SST anomaly in the central and eastern equatorial Pacific (Fig. 1a), corresponding to the ENSO mode. The leading North Pacific modes, NP1, NP2, and NP3 explain the variances of $22 \%, 17 \%$, and $9 \%$, respectively, with NP1 exhibiting a horseshoe pattern dominated by the central loading in the Kuroshio Extension (KOE) region (Fig. 1d).

The atmospheric response to the SST modes is assessed for each atmospheric point over the globe using GEFA (2.7) at $\tau=1$ month, with the base set as $\{$ TP1, TP2, TP3, NP1, NP2, NP3 $\}$ in (2.4)-(2.6). Its statistical significance is estimated with a Monte Carlo test, with the year of the atmospheric data randomly scrambled 1000 times (see LWY08; LW08). Here, we will limit our discussion to the response to TP1 and NP1.

The GEFA response to TP1, as derived from (2.7), recovers the classical atmosphere response pattern to El Niño, which is characterized by a circumglobal response in the tropics and significant teleconnections into the extratropics (Figs. 2a,b). The tropical response is characterized by a pair of baroclinic response with the highs (lows) straddling across the equator in the upper (lower) atmosphere in the central Pacific (at $140^{\circ} \mathrm{W}$ ), as well as a zonally uniform positive response along the 
TABLE 1. The forcing matrix (at lag 1) among the first three SST EOFs of TP, NP, TI, TA, and NA. The bottom row is the magnitude of the PC. Each row and column uses time $t$ and $t-\tau$, respectively (indicated at the top-left corner), in the calculation of the lagged covariance in $m_{i j} \sim C_{y_{i} y_{j}}(\tau) \sim\left\langle y_{i}(t), y_{j}(t-\tau)\right\rangle$. The element $m_{i j}$ represents the weight of the contribution (GEFA response) of the forcing on the $i$ th row to the total EFA response to the forcing on the $j$ th column. Simply speaking, $m_{i j}$ reflects how strongly the forcing on the $i$ th row contributes to the forcing on the $j$ th column (indicated by the right arrow in the leftmost column) or equivalently how strongly the forcing on the $j$ th column can be attributed by the forcing on the $i$ th row. For example, $m_{1 j}$ (first row) represents the contribution of the El Niño mode (TP1) onto all the modes. Alternatively, $m_{i, 1}$ (first column) represents the contribution from all the modes onto the El Niño mode. The forcing matrix $\mathbf{M}$ is valid for any truncation of SST EOFs, because $m_{i j}$ only involves the univariate covariance between each pair of PCs as seen in (2.3c). Bold type denotes elements statistically significant at the $95 \%$ level with a Monte Carlo test with the year of the forcing on the $i$ th row randomly scrambled 1000 times.

\begin{tabular}{|c|c|c|c|c|c|c|c|c|c|}
\hline \multicolumn{10}{|c|}{$\mathbf{M}=\left[m_{i j}\right],(i=1, \ldots, 15 ; j=1, \ldots, 9)$} \\
\hline$t, t-\tau$ & TP1 & ТP2 & TP3 & NP1 & NP2 & NP3 & TI1 & $\mathrm{TI} 2$ & $\mathrm{TI} 3$ \\
\hline $\mathrm{TP} 1 \rightarrow$ & 1 & 0.01 & 0.12 & 0.8 & -0.41 & -0.28 & 0.96 & 1.13 & 0.41 \\
\hline $\mathrm{TP} 2 \rightarrow$ & 0.01 & 1 & -0.03 & 0.11 & -0.4 & -0.06 & 0.03 & 0.2 & 0.02 \\
\hline $\mathrm{TP} 3 \rightarrow$ & -0.01 & 0.01 & 1 & -0.12 & 0.06 & 0.27 & -0.16 & 0.22 & 0.24 \\
\hline $\mathrm{NP} 1 \rightarrow$ & 0.31 & 0.13 & -0.47 & 1 & -0.05 & 0.02 & 0.28 & 0.15 & 0.15 \\
\hline $\mathrm{NP} 2 \rightarrow$ & -0.09 & -0.47 & 0.17 & -0.04 & 1 & -0.04 & 0.07 & -0.23 & -0.04 \\
\hline NP3 $\rightarrow$ & -0.1 & -0.04 & 0.4 & -0.03 & 0.03 & 1 & -0.36 & 0.11 & 0.27 \\
\hline $\mathrm{TI} 1 \rightarrow$ & 0.36 & 0.03 & $-\mathbf{0 . 3 3}$ & 0.24 & -0.03 & -0.63 & 1 & 0.17 & 0.07 \\
\hline TI2 $\rightarrow$ & 0.06 & 0.11 & 0.16 & 0.05 & -0.06 & 0.15 & -0.07 & 1 & 0.04 \\
\hline $\mathrm{TI} 3 \rightarrow$ & 0.01 & 0.02 & 0.19 & -0.03 & 0.02 & 0.11 & 0.02 & 0.04 & 1 \\
\hline TA1 $\rightarrow$ & 0.1 & 0.06 & -0.79 & 0.05 & -0.03 & -0.47 & 0.5 & -0.15 & -0.28 \\
\hline $\mathrm{TA} 2 \rightarrow$ & 0.18 & 0.24 & -0.47 & 0.26 & -0.24 & -0.63 & 0.42 & -0.24 & -0.18 \\
\hline TA3 $\rightarrow$ & 0.05 & -0.02 & -0.02 & 0.08 & 0.05 & 0.03 & 0.12 & -0.01 & 0.05 \\
\hline NA1 $\rightarrow$ & 0.06 & 0.06 & -0.44 & 0.14 & -0.09 & -0.43 & 0.14 & -0.08 & -0.04 \\
\hline NA2 $\rightarrow$ & $-0.08 *$ & $-0.16^{*}$ & 0.08 & -0.14 & 0.03 & -0.02 & -0.13 & -0.09 & 0.23 \\
\hline NA3 $\rightarrow$ & 0.02 & 0.05 & 0.09 & 0.2 & 0.11 & 0.31 & -0.01 & 0.08 & 0.15 \\
\hline$\sigma(\mathrm{PC})$ & 0.42 & 0.20 & 0.13 & 0.26 & 0.23 & 0.17 & 0.23 & 0.14 & 0.12 \\
\hline \multicolumn{10}{|c|}{$\mathbf{M}=\left[m_{i j}\right],(i=1, \ldots, 15, j=10, \ldots, 15)$} \\
\hline$t, t-\tau$ & \multicolumn{2}{|c|}{ TA1 } & TA2 & \multicolumn{2}{|c|}{ TA3 } & NA1 & \multicolumn{2}{|r|}{ NA2 } & NA3 \\
\hline $\mathrm{TP} 1 \rightarrow$ & \multicolumn{2}{|c|}{0.04} & 0.48 & \multicolumn{2}{|c|}{0.5} & 0.13 & \multicolumn{2}{|r|}{-0.5} & 0.25 \\
\hline $\mathrm{TP} 2 \rightarrow$ & \multicolumn{2}{|c|}{0.06} & 0.14 & \multicolumn{2}{|c|}{-0.01} & 0.04 & \multicolumn{2}{|r|}{-0.24} & 0.1 \\
\hline $\mathrm{TP} 3 \rightarrow$ & \multicolumn{2}{|c|}{-0.14} & -0.22 & \multicolumn{2}{|c|}{-0.01} & -0.21 & \multicolumn{2}{|r|}{0.04} & 0.07 \\
\hline $\mathrm{NP} 1 \rightarrow$ & \multicolumn{2}{|c|}{-0.01} & 0.28 & \multicolumn{2}{|c|}{0.28} & 0.09 & \multicolumn{2}{|r|}{-0.22} & 0.54 \\
\hline $\mathrm{NP} 2 \rightarrow$ & \multicolumn{2}{|c|}{0.01} & -0.24 & \multicolumn{2}{|c|}{0.11} & -0.2 & \multicolumn{2}{|r|}{0.02} & 0.19 \\
\hline $\mathrm{NP3} \rightarrow$ & \multicolumn{2}{|c|}{-0.16} & -0.3 & \multicolumn{2}{|c|}{0.06} & -0.26 & \multicolumn{2}{|r|}{0.02} & 0.39 \\
\hline $\mathrm{TI} 1 \rightarrow$ & \multicolumn{2}{|c|}{0.34} & 0.39 & \multicolumn{2}{|c|}{0.33} & 0.17 & \multicolumn{2}{|r|}{-0.16} & -0.02 \\
\hline TI2 $\rightarrow$ & & & -0.08 & & & -0.02 & & 0.01 & 0.1 \\
\hline $\mathrm{TI} 3 \rightarrow$ & & & -0.07 & & & -0.07 & & 0.08 & 0.03 \\
\hline TA1 $\rightarrow$ & & & -0.02 & & & 0.11 & & -0.14 & -0.24 \\
\hline $\mathrm{TA} 2 \rightarrow$ & & & 1 & & & 0.86 & & -0.15 & -0.03 \\
\hline TA3 $\rightarrow$ & & & -0.01 & & & -0.16 & & 0.03 & 0.13 \\
\hline NA1 $\rightarrow$ & & & 0.56 & & & 1 & & 0.01 & 0.02 \\
\hline $\mathrm{NA} 2 \rightarrow$ & & & -0.07 & & & -0.07 & & 1 & -0.03 \\
\hline NA3 $\rightarrow$ & & & -0.03 & & & -0.03 & & 0.06 & 1 \\
\hline$\sigma(\mathrm{PC})$ & & & 0.23 & & & 0.22 & & 0.19 & 0.17 \\
\hline
\end{tabular}

equator in the upper and lower atmosphere. This tropical response further excites an equivalent barotropic wavelike disturbance toward North America, with a negative over the Aleutian low and a positive over northern North America, which resembles the Pacific-North American (PNA) pattern (Wallace and Gutzler 1981). A similar wave-like response is also generated over the South Pacific with a low over New Zealand and a high near the southern tip of Argentina, which resembles the PacificSouth America (PSA) pattern (Robertson and Mechoso
2003). Overall, the pattern of the GEFA response to TP1 resembles closely the classical response to ENSO, as indicated in the ENSO-driven tropical Northern Hemisphere mode (TNH; Trenberth et al. 1998) and the composite analysis (e.g., Liu and Alexander 2007). The magnitude of the $\mathrm{Z} 250$ response, after a multiplication of the amplitude of its PC (0.42; see Table 1$)$, following (2.8), is about $30 \mathrm{~m}$, which is also comparable with previous composite analyses. This atmospheric response pattern, at the first order, can be understood as a baroclinic 
a) GEFA Z250 Rsp to TP1, $\sigma(\operatorname{TP} 1)=0.42^{\circ} \mathrm{C}$

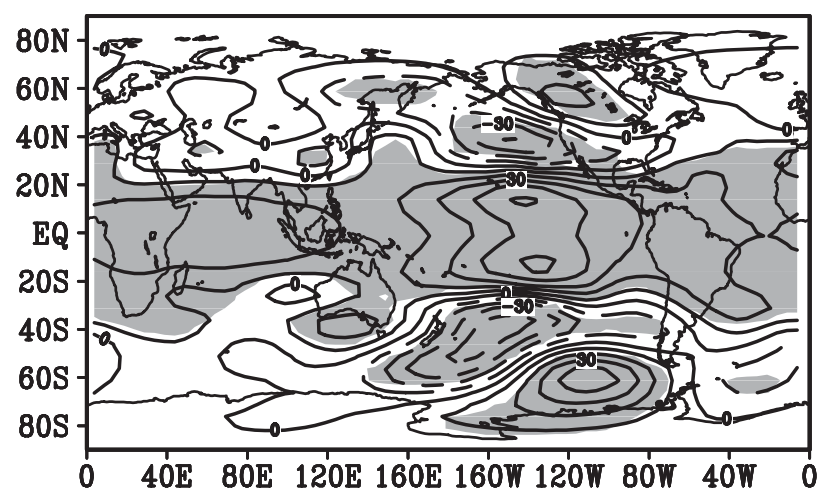

b) GEFA Z850 Rsp to TP1, $\sigma(\mathrm{TP} 1)=0.42^{\circ} \mathrm{C}$

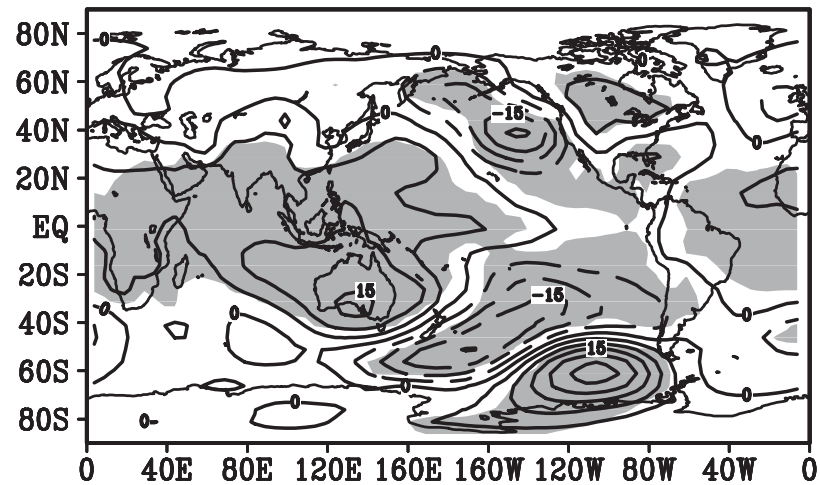

c) GEFA Z250 Rsp to NP1, $\sigma(\mathrm{NP} 1)=0.26^{\circ} \mathrm{C}$

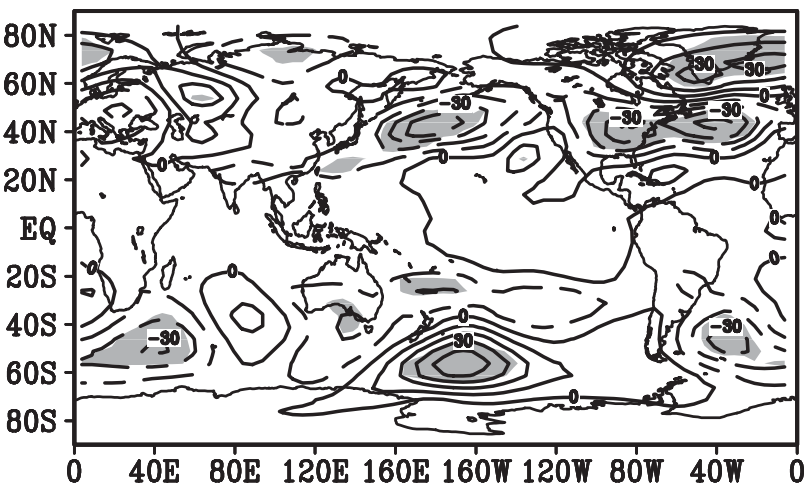

d) GEFA Z850 Rsp to NP1, $\sigma(\mathrm{NP} 1)=0.26^{\circ} \mathrm{C}$

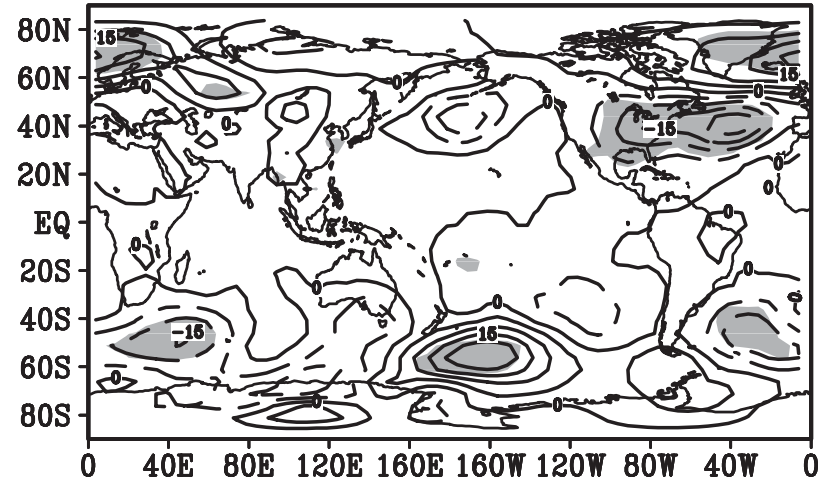

FIG. 2. GEFA response sensitivity of (a) Z250 (CI $\left.=10 \mathrm{~m}^{\circ} \mathrm{C}^{-1}\right)$ and (b) $\mathrm{Z} 850\left(\mathrm{CI}=5 \mathrm{~m}^{\circ} \mathrm{C}^{-1}\right)$ to TP1. (c),(d) As in (a),(b), but to NP1. The response is assessed with the first three EOFs in both TP and NP (solid lines for positive and dashed lines for negative; $90 \%$ significance shaded).

equatorial Rossby wave response to a deep tropical heating associated with the warm equatorial SST (Gill 1980) and the subsequent barotropic Rossby wave propagation toward the extratropics (Hoskins and Karoly 1981). It will be shown later, however, that the mechanism of this ENSO response can be further understood in light of additional GEFA analyses.

The robustness of the GEFA response is tested from its sensitivity to the lag and EOF truncation for assessment. The lag dependence for Z250 is shown in pattern correlation and amplitude ratio of the GEFA response estimated at various lags relative to that at $\tau=1$ (Fig. 3a). The robustness of the response in different regions is illustrated for 3 domains: tropics $\left(20^{\circ} \mathrm{S}-20^{\circ} \mathrm{N}\right)$, Northern Hemisphere $\left(\mathrm{NH} ;>20^{\circ} \mathrm{N}\right)$ and North Pacific $\left(20^{\circ}-60^{\circ} \mathrm{N}\right.$, $\left.100^{\circ} \mathrm{E}-100^{\circ} \mathrm{W}\right)$. Relative to lag 1 , the lag 2 response has almost the same pattern, with the amplitude about $10 \%$ larger in the tropical and global domains and about $30 \%$ larger for the NH and North Pacific. Therefore, GEFA estimate is very stable at lag 2, especially in the tropics. A visual examination shows that the major centers remain the same in lag 2 (and even lag 3; not shown) as in lag 1. Because global atmospheric response takes about 1-2 months (Hoerling et al. 2004; Ferreira and Frankignoul 2005), we consider lag 2 as a useful sensitivity test for the lag 1 estimate. As the lag increases further, the diminishing autocovariance among SSTs leads to a significant increase of sampling error. As a result, for lags beyond 4, the GEFA response deteriorates dramatically, as seen in the sharp decrease of pattern correlation and increase in amplitude. The dependence of the GEFA response to EOF truncation is seen similarly in the pattern correlation and amplitude ratio relative to the standard case of three EOFs (Fig. 3b). Both the pattern correlation and amplitude ratio remain close to 1 before the EOF truncation increases beyond 14, reflecting a stable GEFA response to EOF truncation.

\section{b. Response to North Pacific SST}

In contrast to the atmospheric response to tropical SST, the atmospheric response to North Pacific SST presents a real challenge, because the atmospheric response to extratropical SST remains poorly understood, 

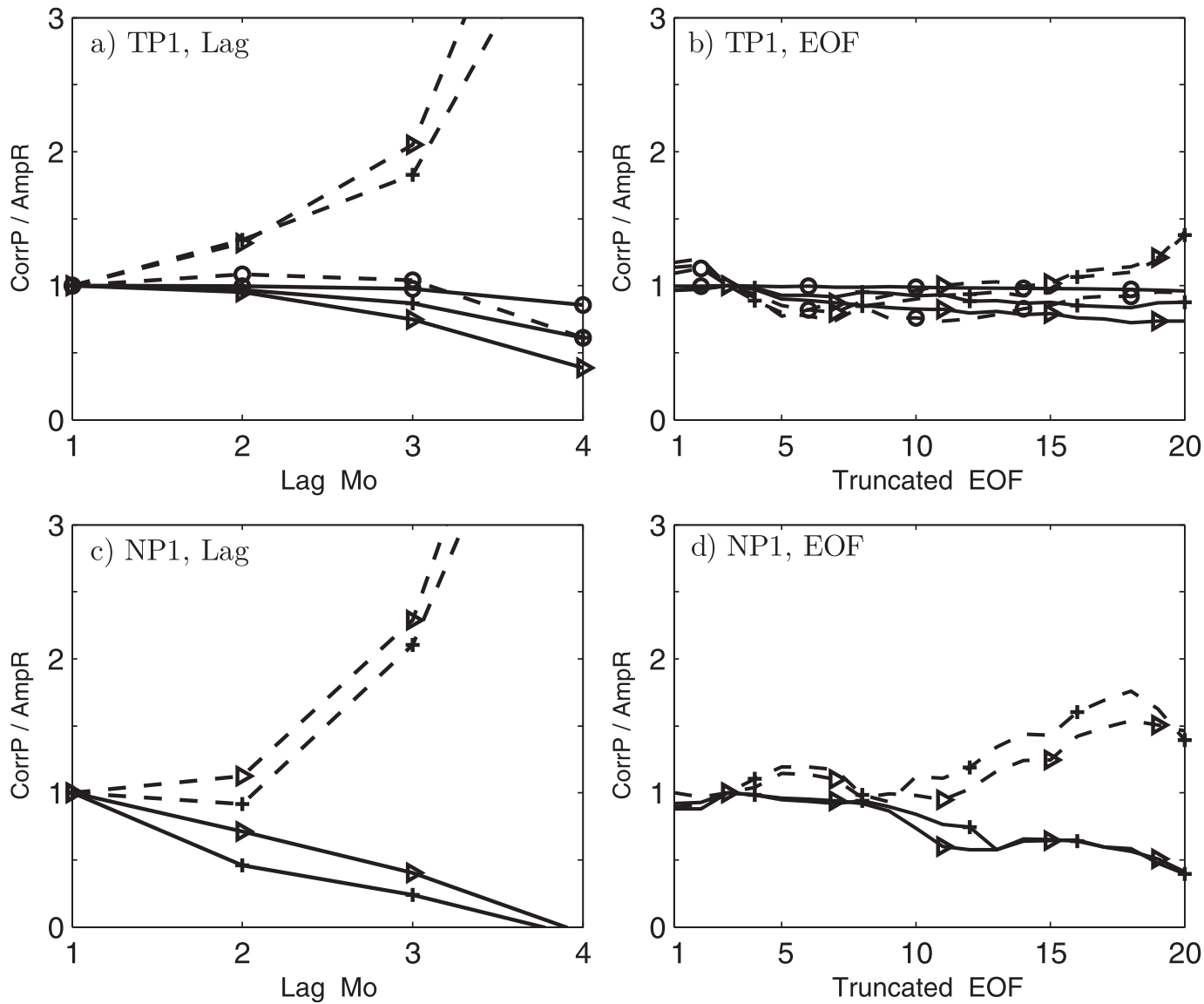

FIG. 3. The sensitivity of the Z250 GEFA responses to lag and EOF truncation in pattern correlation (solid lines) and amplitude ratio (dash lines). GEFA is performed using the same number of regional SST EOFs in TP and NP. (a) Response to TP1 with pattern correlation and amplitude ratio estimated at various lags relative to the standard case, which uses lag 1 and 3 EOFs in both basins. The sensitivity is calculated for different atmospheric regions: tropics $\left(20^{\circ} \mathrm{S}-20^{\circ} \mathrm{N}\right.$; blue $), \mathrm{NP}\left(20^{\circ}-60^{\circ} \mathrm{N}, 100^{\circ}-280^{\circ} \mathrm{E}\right.$; black $), \mathrm{NH}\left(>20^{\circ} \mathrm{N}\right.$; green $)$. (b) As in (a), but for different EOF truncations. (c),(d) As in (a),(b), but for the response to NP1, with only the NH response shown.

with neither a clear observational target nor a consistent set of model simulations (Kushnir et al. 2002). One of our original objectives here is to explore if a robust observational signal can be identified using GEFA. Here, using the SST base $\{$ TP1, TP2, TP3, NP1, NP2, NP3 $\}$, the overall GEFA response to NP1 (Figs. 2c,d) is estimated using (2.7). The GEFA response to NP1 thus derived is much weaker than that to TP1, which is consistent with the expectation of a weaker atmospheric response sensitivity to SST in the extratropics than in the tropics. Nevertheless, there is still a modest but significant response in the $\mathrm{NH}$, which is characterized by a wave-like pattern of equivalent barotropic structure. A cold KOE SST (Fig. 1d) forces a modest local response with a negative GPH over the Aleutian low in the so-called warm SST-ridge (or cold SST-trough) response. This is consistent with our recent assessment of winter atmospheric response to KOE SST using EFA (Liu and $\mathrm{Wu}$
2004; Liu et al. 2007). This warm SST-ridge response is likely to be caused by a dominant winter atmospheric response associated with eddy-mean flow interactions (Peng et al. 1997; Peng and Whitaker 1999). The most significant GEFA response, interestingly, occurs downstream over the North Atlantic as a north/south dipole that resembles a negative NAO (Wallace and Gutzler 1981). This atmospheric response over the North Pacific and North Atlantic are rather stable to lags and EOF truncations. The lag sensitivity (Fig. 3c) shows that, at lag 2, the pattern correlation is 0.8 for the $\mathrm{NH}$ and $\sim 0.5$ for the North Pacific and that the amplitudes remain little changed. All the major action centers in lag 1 can be identified visually in lag 2 (not shown). Beyond lag 4, the response is dominated by sampling errors. The EOF truncation sensitivity (Fig. 3d) shows that the pattern correlation and amplitude ratio remains close to 1 unless the EOF truncation increases 
beyond 8. A comparison of Figs. 3c,d with Figs. 3a,b shows that the GEFA response to TP1 is more robust than that to NP1. This is expected because of the larger magnitude and longer persistence time of the tropical SST and the weaker internal variability in the tropical atmosphere.

The GEFA response to NP1, if true, raises an interesting question: how does NP1 influence NAO? Here, we note that this North Pacific-Atlantic response pattern resembles closely to the winter atmospheric teleconnection pattern known as the Aleutian-Icelandic seesaw (Honda et al. 2001, 2005). This teleconnection is initiated by an accumulation of atmospheric wave activity in the Aleutian low region in early to midwinter. Part of the wave activity then propagates across North America in the form of stationary Rossby wave train, forming the stationary anomaly over the North Atlantic. A similar remote teleconnection response has also been produced in an AGCM with prescribed atmospheric heating over the North Pacific region (Gritsun and Branstator 2007) and in coupled models in which an ocean temperature anomaly is initialized in the $\mathrm{KOE}$ region (Liu and Wu 2004; Liu et al. 2007). Finally, it is interesting that Figs. $2 \mathrm{c}$, d also show a remote response to NP1 in a wave-like pattern around the Southern Ocean. The mechanism for this remote response, however, is unclear. It is not even clear if this remote response is physically real. Nevertheless, in principle, this remote $\mathrm{SH}$ response could be induced by an interhemispheric atmospheric teleconnection, such as the penetration of stationary waves across the equator in the region of westerly duct, although these activity centers appear to be well west of the waveguide (Webster and Holton 1982).

The overall much stronger effect of tropical SST forcing than North Pacific SST forcing, especially in the tropics, is seen clearly in the response sensitivities (Figs. 2a,b versus Figs. 2c,d). For the observed SST variability, this response magnitude [see (2.8)] to the tropical forcing is further enhanced by a greater SST variability in the tropical Pacific than in the North $\mathrm{Pa}$ cific $\left[\sigma\left(\mathrm{PC}_{\mathrm{TP} 1}\right)=0.42, \sigma\left(\mathrm{PC}_{\mathrm{NP} 1}\right)=0.26\right.$; Table 1]. Even in the Aleutian low region, where the response sensitivity to NP1 (20-40 m ${ }^{\circ} \mathrm{C}^{-1}$ on Z250; Fig. 2c) is comparable with the ENSO teleconnection from TP1 (Fig. 2a), the response magnitude to $\mathrm{TP} 1\left(0.42^{\circ} \mathrm{C} \times 40 \mathrm{~m}^{\circ} \mathrm{C}^{-1}=\right.$ $17 \mathrm{~m})$ is larger than that to $\mathrm{NP} 1\left(0.26^{\circ} \mathrm{C} \times 40 \mathrm{~m}{ }^{\circ} \mathrm{C}^{-1}=\right.$ $10 \mathrm{~m})$. Therefore, for the observed climate variability, the Aleutian low is affected more by the remote tropical Pacific SST than by the local North Pacific SST, at monthly to interannual time scales.

The robustness of the GEFA response we have shown was confirmed by two additional tests (not shown). First, our GEFA response to regional EOFs is confirmed by a GEFA response using the rotated EOFs (REOFs) of the SST in the entire tropical-North Pacific region. Unlike the EOFs of the entire tropical-Pacific region, the REOFs tend to be localized and therefore should compare better with our regional EOF studies here. The REOFs 1, 2, and 3 resemble our regional EOFs TP1, TP2, and NP1, respectively. Second, the GEFA response to both TP1 and NP1 is also found to be consistent with the traditional univariate analysis of the residual variability with a prior filter of external forcing (appendixes A and B).

\section{c. Total (EFA) response}

It is also interesting to examine the total (EFA) responses of the atmosphere to TP1 and NP1 in light of their GEFA responses, because the difference between the EFA response and the GEFA response is informative of the potential contribution from other correlated SST forcings. The total response of Z250 to TP1 (Fig. 4a) resembles closely the GEFA response (Fig. 2a). This occurs because the ENSO variability forcing is so dominant in the observation such that the impact of other SST forcings in the tropical North Pacific region are negligible. In contrast, the total response to NP1 (Fig. 4b) differs significantly from the GEFA response (Fig. 2c), with the former including a dominant ENSO response (Fig. 2a) in the tropics and extratropics. This implies a significant tropical Pacific contribution onto the NP1 forcing, or the total response to NP1 includes a significant contribution from the atmospheric response to TP1. This is well understood, because tropical Pacific SST has a significant impact on North Pacific SST through the atmospheric teleconnection (e.g., Alexander et al. 2002; Newman et al. 2003).

The difference between the total response and GEFA response can be better understood in terms of the forcing matrix (Table 1). We first examine the response to TP1. In the forcing matrix, $m_{1 j}$ (first row) represents the contribution of El Niño mode (TP1) onto all the modes, whereas $m_{i, 1}$ (first column) represents the contribution from all the modes onto the El Niño mode. The strong contribution of the El Niño onto other modes is seen clearly from its large contribution weights $m_{1 j}$ on other modes (except locally on other tropical Pacific modes), most of which differ significantly from zero. In comparison, El Niño is affected potentially only by two modes, NP1 and TI1, with the weights $m_{41}=0.31$ and $m_{71}=0.36$, respectively. From the global perspective, the contribution of NP1 onto TP1 is small, because it is confined in the isolated extratropical regions where the GEFA response to NP1 is significant ( $b_{4}$; Figs. $\left.2 \mathrm{c}, \mathrm{d}\right)$. 
a) EFA Z250 Rsp to TP1, $\sigma(\mathrm{TP} 1)=0.42^{\circ} \mathrm{C}$

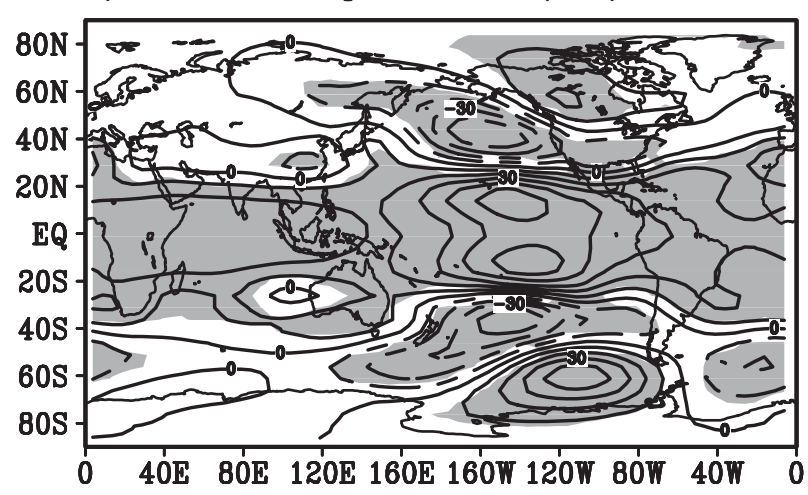

b) EFA Z250 Rsp to NP1, $\sigma(\mathrm{NP} 1)=0.26^{\circ} \mathrm{C}$

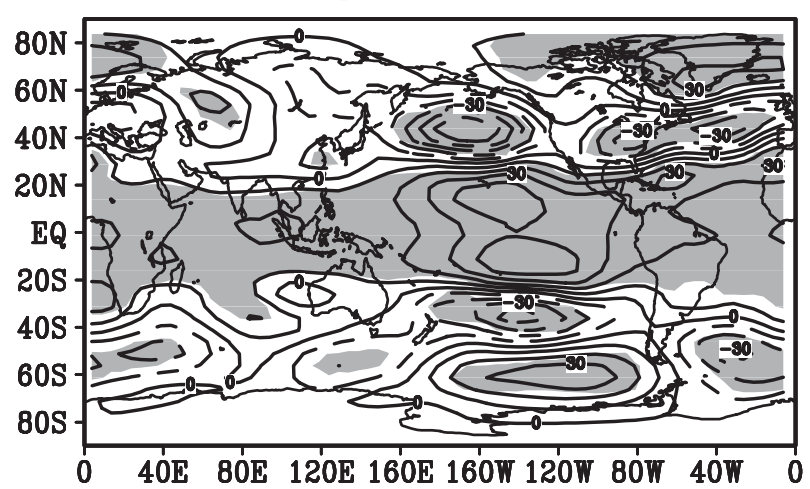

c) EFA Z250 Rsp to TI1, $\sigma(\mathrm{TI} 1)=0.23^{\circ} \mathrm{C}$

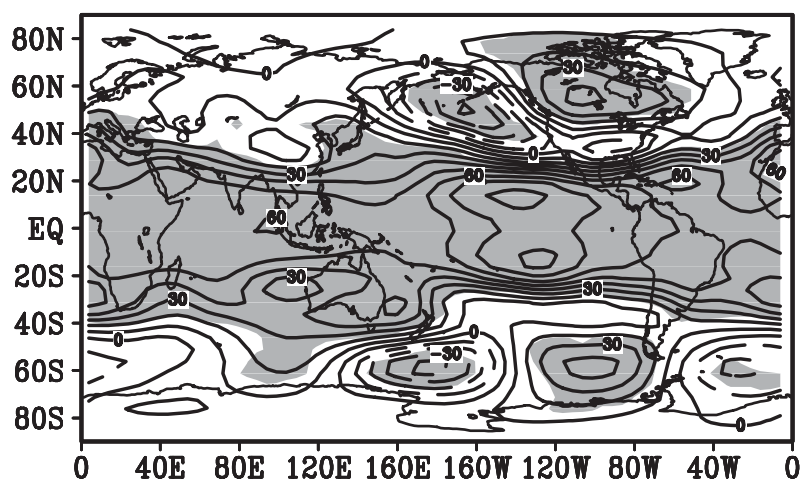

FIG. 4. The total (EFA) response sensitivity of Z250 to (a) TP1, (b) NP1, and (c) TI1 (solid contours for positive, and dashed contours for negative values; $\mathrm{CI}=10 \mathrm{~m}^{\circ} \mathrm{C}^{-1}$, with $90 \%$ significance level shaded).

Therefore, the response to TP1 over most of the globe is dominated by the local forcing itself $\left(m_{11}=1\right)$ or symbolically following (2.3), $a_{1}=\sum_{i=1}^{6} b_{i} m_{i 4} \approx b_{1}$ (the contribution of TI1 will be discussed later).

In contrast to TP1, the contribution to NP1 (fourth column; $\left.m_{i 4}\right)$ is dominated by the remote forcing TP1 $\left(m_{14}=0.8\right)$ and the local forcing NP1 itself $\left(m_{44}=1\right)$ : symbolically, $a_{4}=\sum_{i=1}^{6} b_{i} m_{i 4} \approx b_{1} m_{14}+b_{4}$. Furthermore, the GEFA response to TP1 is strong over most of the globe $\left(b_{1} \gg b_{4}\right.$; Figs. $2 \mathrm{c}, \mathrm{d}$ versus Figs. $\left.2 \mathrm{a}, \mathrm{b}\right)$, especially in the tropics and the regions of PNA and PSA wave trains. Therefore, in these regions, the total response to NP1 is dominated by the remote ENSO impact $\left(a_{4} \approx b_{1} m_{14}\right)^{3}$

In short, our GEFA assessment in the tropicalextratropical North Pacific shows a dominant and robust ENSO response with a global teleconnection and a modest but significant response to the North Pacific SST on Aleutian low and downstream on NAO.

\section{Atmospheric responses to tropical-extratropical Northern Hemisphere SSTs}

Our GEFA response so far has been confined to SST forcing within the tropical-North Pacific. However, previous observational and modeling studies have shown strong evidence of atmospheric response to oceans outside the Pacific, such as the tropical Indian Ocean (e.g., Kumar and Hoerling 2003, hereafter KH03; Hoerling et al. 2004) and tropical (Sutton and Hodson 2003; Wu et al. 2005) and North (e.g., Palmer and Sun 1985; Czaja and Frankignoul 2002) Atlantic Ocean. To separate the impact of SST forcing from other oceans, we will expand GEFA to SSTs in the tropical Indian Ocean as well as the tropical and North Atlantic Ocean. We will use for SST forcing a grand set of 15 regional SST EOFs, which consists of 3 EOFs from 5 oceans: the tropical Indian Ocean, tropical Atlantic, North Atlantic, tropical Pacific, and North Pacific Oceans. [The result later is robust when the SST modes are further expanded to all the oceans, including those in the Southern Hemisphere (not shown).]

The Indian Ocean modes, TI1, TI2, and TI3, have explained variances of $34 \%, 13 \%$, and $9 \%$, respectively, with TI1 as the Indian Ocean monopole mode that is strongly forced by the Pacific ENSO (Fig. 1b; e.g., Klein

\footnotetext{
${ }^{3}$ It should be pointed out that the much larger impact of TP1 on the NP1 than the reverse is mainly due to the difference in mode variance and persistence time, rather than the cross covariance. Although the lagged cross covariance is only $10 \%$ larger for TP1 leading NP1 (0.052) than that for NP1 leading TP1 (0.048), the contribution weight of TP1 onto NP1 $\left(m_{14}=0.8\right)$ is more than twice that of NP1 onto TP1 $\left(m_{41}=0.31\right)$. Indeed, the contribution weight $m_{i j} \equiv C_{i j}(\tau) / C_{j j}(\tau)$ is proportional to the cross covariance but inversely proportional to the autocovariance, the latter being the product of the variance and the lagged autocorrelation of the $j$ th mode. The NP1 has a much smaller variance $(0.07)$ and somewhat smaller autocorrelation (0.86) than the TP1 (0.18 and 0.96). This leads to a contribution factor $m_{14}$, more than twice that of $m_{41}$. In some sense, one may think of the mode's lagged autocovariance as its inertial. Relative to TP1, NP1 has a much smaller inertial and therefore is much easily affected by other forcings.
} 
a) GEFA Z250 Rsp to TP1, $\sigma(\mathrm{TP} 1)=0.42^{\circ} \mathrm{C}$

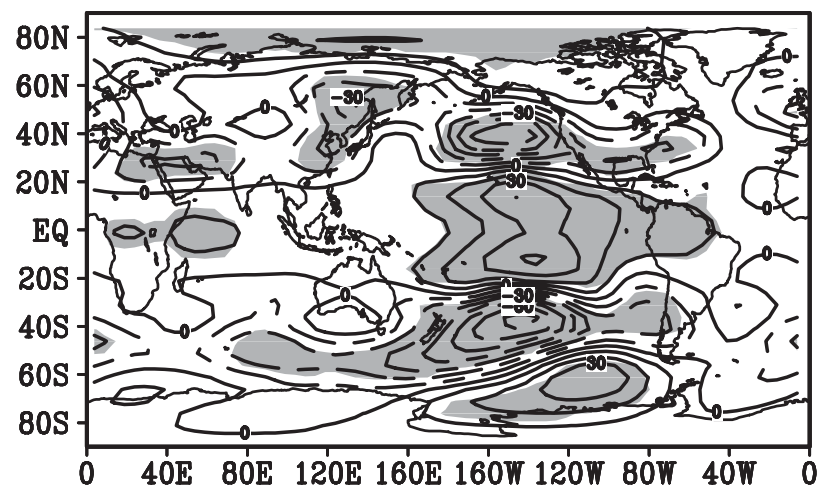

b) GEFA Z250 Rsp to TI1, $\sigma(\mathrm{TI} 1)=0.23^{\circ} \mathrm{C}$

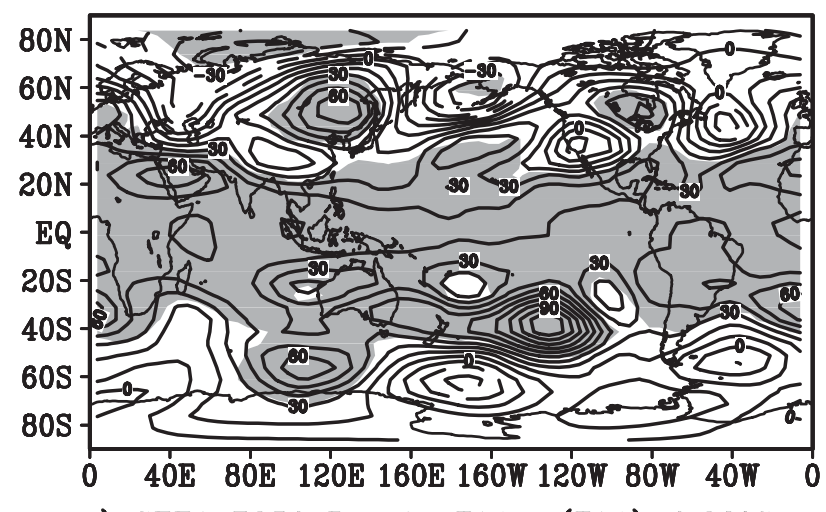

c) GEFA Z250 Rsp to TA1, $\sigma(\mathrm{TA} 1)=0.28^{\circ} \mathrm{C}$

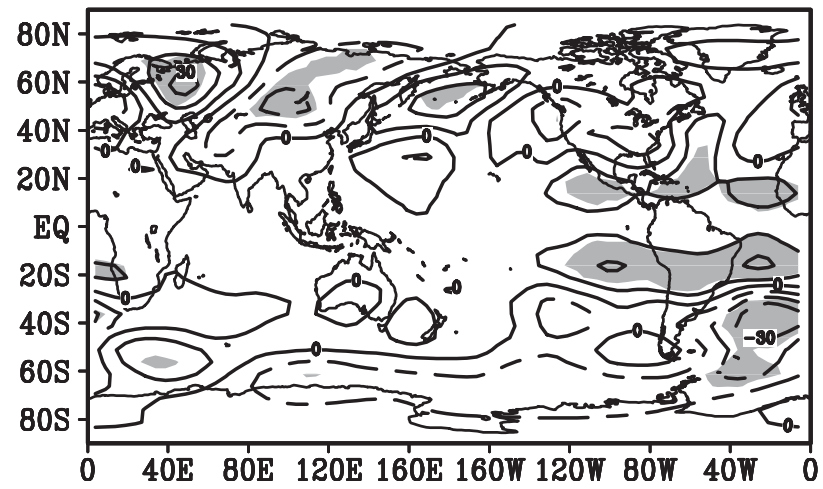

et al. 1999; Yang et al. 2007). The tropical Atlantic modes, TA1, TA2, and TA3, have the explained variances of $38 \%, 24 \%$, and $7 \%$, respectively, with TA1 as a monopole with a broad maximum loading spanning from the equator across the tropical South Atlantic (Fig. 1c). The North Atlantic modes, NA1, NA2, and NA3, have explained variance of $19 \%, 15 \%$, and $12 \%$, respectively, with NA1 as a tripole mode (Fig. 1e). It should be noted here that, unlike ENSO, which is a physical mode, the physical entities of some SST modes here remain controversial (Houghton and Tourre 1992; Allen et al. 2001; Yamagata et al. 2003). d) GEFA Z250 Rsp to NP1, $\sigma(\mathrm{NP} 1)=0.26^{\circ} \mathrm{C}$

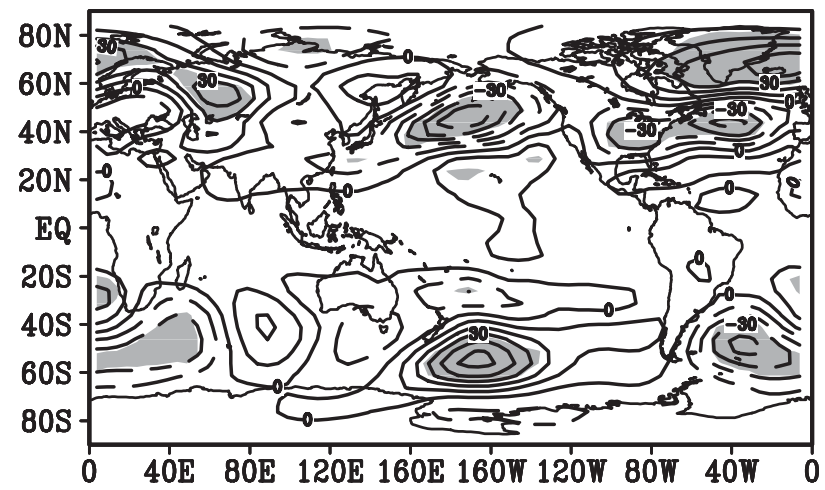

e) GEFA Z250 Rsp to NA1, $\sigma(\mathrm{NA1})=0.22^{\circ} \mathrm{C}$

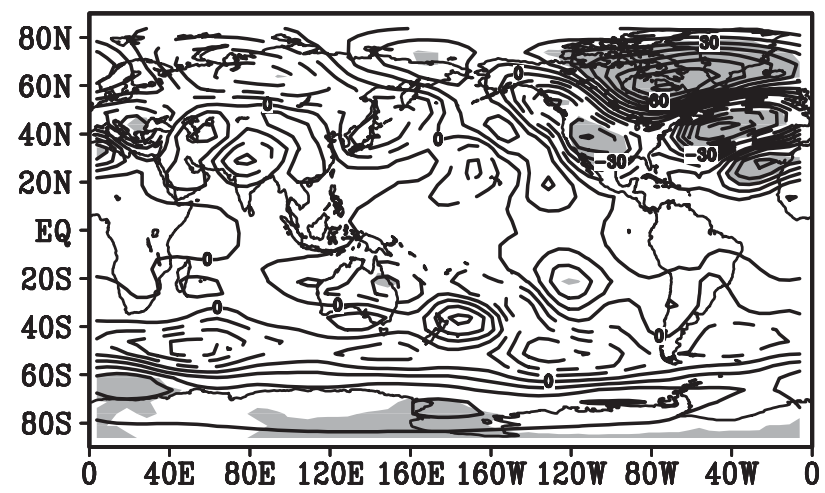

FIG. 5. Z250 GEFA response sensitivity to the SST EOF1 of each basin of the tropical-extratropical NH oceans: GEFA responses to (a) TP1, (b) TI1, (c) TA1, (d) NP1, and (e) NA1 (solid line for positive and dashed line for negative; $\mathrm{CI}=10 \mathrm{~m}^{\circ} \mathrm{C}^{-1}$, with $90 \%$ significance level shaded). The responses are assessed using the first three EOFs of the TP, TI, TA, NP, and NA basins.

\section{a. Separating tropical Pacific forcing from tropical Indian Ocean forcing}

With the grand set of 15 SST modes, the most dramatic change occurs for the GEFA response to TP1, as seen by comparing the responses of Z250 after (Fig. 5a) and before (Fig. 2a) the expansion. This is in contrast to the response to NP1, which remains largely unchanged (Fig. 5d versus Fig. 2c). The most significant change in the response to TP1 is the disappearance of the circumglobal positive anomaly in the tropics such that the tropical atmospheric response to TP1 is now confined mainly 
in the tropical eastern Pacific as a pair of Rossby waves (Fig. 5a). Furthermore, in the extratropics, the PNA pattern is weakened significantly in its northernmost lobe over the North America, although the PSA pattern appears to remain largely unchanged.

The dramatic change of the GEFA response to TP1 is caused by the tropical Indian Ocean forcing. The GEFA response to TI1 (Fig. 5b) is dominated by a circumglobal tropical response, which closely resembles the missing part of the response to TP1 between Fig. 2a and Fig. 5a. In the extratropics, TI1 also excites significant teleconnection responses in both hemispheres. For example, it builds a positive anomaly over the North America, which seems to be a major contributor to the North American lobe of the PNA response in Fig. 2a. Overall, the teleconnection pattern in the northern mid-high latitude also has a much stronger zonal mean component than that to TP1. Therefore, the ENSO response to TP1 derived for SST modes in the Pacific (Fig. 2a), like the total response to TP1 (Fig. 4a), includes a significant contribution from the tropical Indian Ocean forcing, especially for the zonally symmetric circumglobal tropical response.

TI1 is the mode with the greatest contribution to TP1 response. The significant impact of TI1 on TP1 can be seen in the contribution weight $m_{71}=0.36$ (Table 1) as well as its great GEFA response over the globe that is comparable with the TP1 $\left(b_{7} \sim b_{4}\right.$; Fig. $5 \mathrm{~b}$ versus Figs. $2 \mathrm{a}, \mathrm{c})$. Therefore, TI 1 is the only mode that has a significant contribution to TP1 for global atmospheric response. Specifically, the overall response to TI1 (Fig. 5b) has a somewhat larger response sensitivity (maximum $50 \mathrm{~m}^{\circ} \mathrm{C}^{-1}$ versus $40 \mathrm{~m}^{\circ} \mathrm{C}^{-1}$ ) and a much broader spatial extent than that to TP1 (Fig. 5a). The response magnitude to the observed variability of TP1, however, can be substantially larger than that of TI1 in some regions, because the former has twice the amplitude of the latter (0.42 versus 0.23 ; Table 1$){ }^{4}$

The major feature of our GEFA response to TI1 seems to be consistent with previous studies, although most previous works have studied the seasonal atmospheric response to tropical Indian Ocean, rather than the year-round response here. In the tropics, for example, both observational and modeling studies (KH03) show a direct atmospheric response to the eastern $\mathrm{Pa}-$ cific SST occurring mainly in winter and confined over the eastern tropical Pacific. This direct response pattern

\footnotetext{
${ }^{4}$ The dominant interaction between the Pacific El Niño (TP1) and Indian Ocean monopole (TI1) is further confirmed in the traditional residual analysis (appendix B). There, it is shown that the GEFA response to TP1 or TI1 can be recovered using the univariate EFA as long as the other mode is filtered out.
}

bears a strong similarity to our GEFA response to TP1 in Fig. 5a. There is also a significant zonally symmetric response lingering into the following summer that is found to be forced by the tropical Indian Ocean SST. This zonally symmetric response, which appears to be caused by the rapid propagation of equatorial Kelvin waves, closely resembles our GEFA response to TI1 (Fig. 5b). Our GEFA response to TI1 is also consistent with observational and modeling studies, which shows a significant enhancement of the basin-wide tropical Indian Ocean SST on the South Asia high (Lau et al. 2005; Yang et al. 2007), as indicated by the positive Z250 anomaly over South/East Asia (Fig. 5b). Remotely in the extratropics, recent modeling studies suggest that a warm tropical Indian Ocean may generate a significant response with a positive NAO (Hoerling et al. 2004; SanchezGomez et al. 2008; Hodson et al. 2010). Furthermore, the overall NH response has a notable zonally symmetric component, which reflects a poleward shift of the $\mathrm{NH}$ midlatitude westerlies and likely involves eddymean flow interactions (Seager et al. 2003), similar to the positive phase of the northern annular mode (NAM; Thompson et al. 2003). This zonally symmetric response to tropical Indian Ocean is in contrast to the atmospheric response to the eastern equatorial Pacific, the latter generating a PNA-like wave train. These features appears to be captured in our GEFA response, in which a warm TI1 forces a significant response, which has a sign consistent with a positive NAO over the North Atlantic sector, or a positive NAM in the entire northern mid and high latitudes (Fig. 5b).

Finally, the different patterns of the tropical atmospheric response to TP1 and TI1 are also consistent with the evolution of the atmospheric response during the ENSO cycle. The strong local response to TP1 (Fig. 5a), the overall strong response to the combined TP1 and TI1 (Fig. 2a) and the broad circumglobal response to TI1 (Fig. 5b), resemble closely the atmospheric responses to El Niño in the early phase (-July), peak phase (January), and late phase (+July), respectively, as seen in the composite of ENSO evolution (middle column of Fig. 5 in KH03); these three phases of the responses are accompanied by the SST anomalies that are dominated in the Pacific (early phase), in both the Pacific and Indian Oceans (peak phase), and in the Indian Ocean (late phase), respectively (left column of Fig. 5 in KH03). This change of atmospheric response through the ENSO cycle can be interpreted in terms of our GEFA response as follows: In the early phase, the SST anomaly is significant only in the Pacific (as TP1), and therefore the atmosphere is dominated by the local response as that to TP1 (Fig. 5a); in the peak phase, significant SST variability is also generated in the Indian Ocean (as TI1) by the 

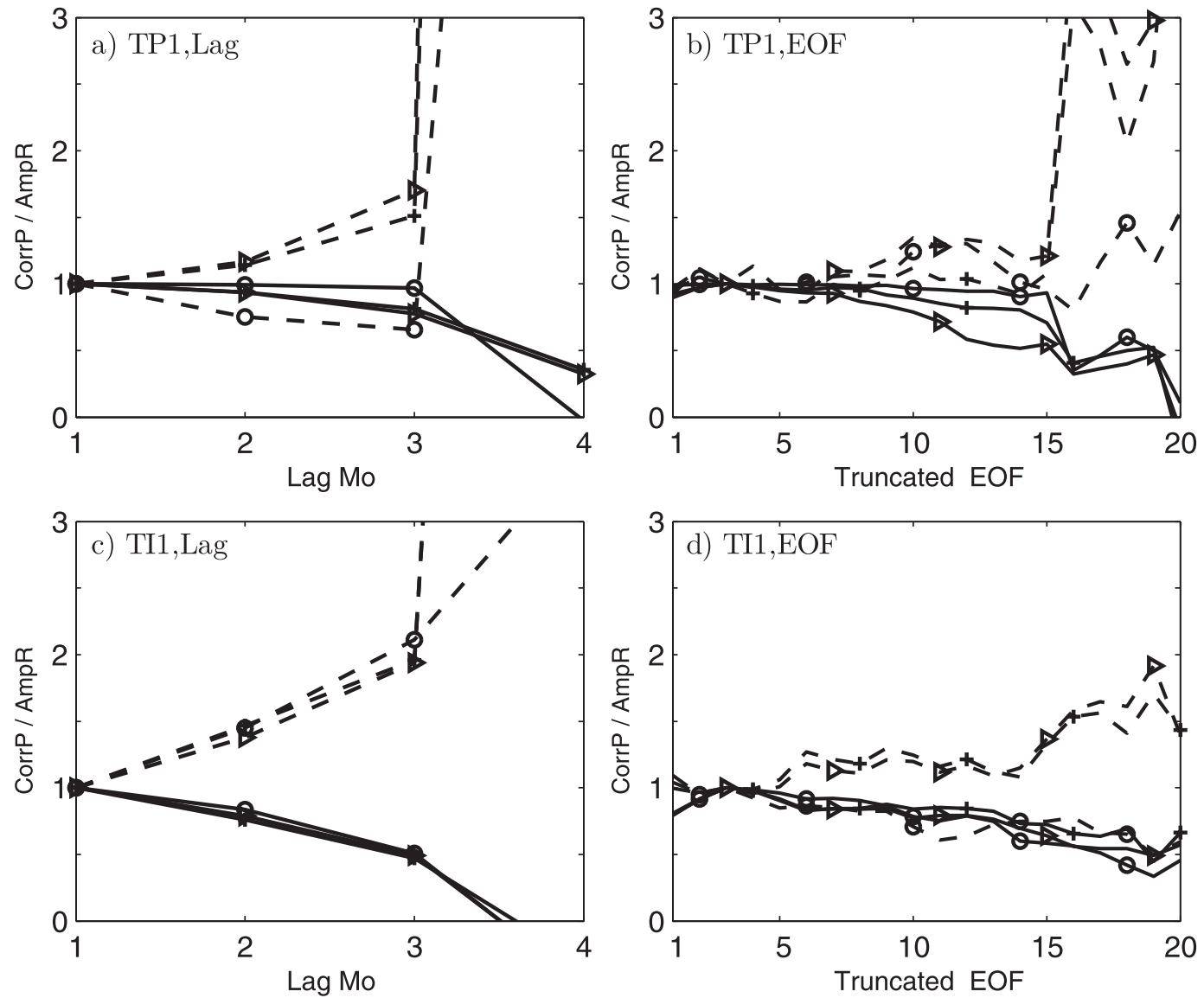

FIG. 6. As in Fig. 3, but for the assessment using the first three EOFs of five tropical-extratropical Northern Hemisphere oceans: (a) the pattern correlation (solid) and (b) the amplitude ratio (dashed) for different lags and EOF truncations for the response to TP1. (c),(d) As in (a),(b), but for the response to TI1.

TP1, and therefore the atmospheric response consists of a response to both TP1 and TI1 (Fig. 2a); in the late phase, El Niño decays in the Pacific, and therefore the atmospheric response is caused mainly by the SST anomaly in the Indian Ocean (Fig. 5b). A consistent evolution of atmospheric response during ENSO can also been seen in the lagged regression of the atmospheric response to El Niño (e.g., Fig. 2 of Chiang and Sobel 2002). Given all these consistent evidences, we believe that the different GEFA responses to TP1 and TI1 are reasonable and robust.

\section{b. Robustness of the tropical forcing}

The GEFA responses to tropical Pacific and tropical Indian Ocean forcings seem to be rather robust with respect to lags and EOF truncations. Similar to Figs. $3 a, b$, Figs. $6 a, b$ show the sensitivity of the response to TP1 with respect to lags and EOF truncations but now using the expanded SST EOFs in five oceans. It is seen that both the pattern and amplitude remain stable at lags 2 and 3. The pattern and amplitude also remain stable for EOF truncations to mode 7. Similarly, the GEFA response to TI1 appears rather stable at lags 2 and 3 and to EOF truncation 5 (Figs. 6c,d). Finally, our GEFA response is also consistent with a traditional residual assessment to TP1 and TI1, after filtering TI1 and TP1, respectively (appendixes A and B).

Our GEFA assessment identified robust global atmospheric response to tropical ocean forcings in the Pacific and Indian Oceans. As discussed earlier, the GEFA response to TP1 estimated using Pacific SSTs (Fig. 2a) is similar to the total response to TP1 (Fig. 4a). This response is now shown to consist of two direct responses, one to the eastern Pacific SST (Fig. 5a) and the other to a basin-wide Indian Ocean SST (Fig. 5b). The latter reflects largely an indirect response to TP1, because TI1 is driven primarily by TP1 through the atmospheric teleconnection associated with ENSO (e.g., Klein et al. 1999; Lau et al. 2005). The strong TP1 influence on TI1 can also be seen in the difference between the total EFA response (Fig. 4c) and the GEFA response (Fig. 5b). 
Therefore, it is still meaningful to call the total response to TP1 as the total response to ENSO, with the ENSO forcing being interpreted as the primary SST variability in the Pacific and the induced secondary SST variability in the Indian Ocean.

\section{c. The role of Atlantic forcing}

We now briefly discuss the atmospheric responses to the SST variability in the North Atlantic and tropical Atlantic. The overall GEFA response to NA1 or TA1 (Figs. 5c,e) is much weaker than that to TP1 or TI1 (Figs. $5 a, b)$ but comparable with that to NP1 (Fig. 5d). Furthermore, the GEFA response to NA1 or TA1 tends to be confined locally in the Atlantic region. These features are rather robust to the lag and EOF truncation (not shown). The weak response to Atlantic forcing partly explains why the major features of the GEFA responses to other ocean modes, such as TP1, TI1, and NP1, are insensitive to NA1 and TA1.

More specifically, the response to the Atlantic Niño TA1 is confined mainly in the tropical Atlantic and nearby continents (Fig. 5c). With the maximum SST south of the equator (Fig. 1c), upper atmosphere exhibits a high pressure maximum south of the equator, which is consistent with the southward migration of the convection region and ITCZ.

The GEFA response to the tripole SST of NA1 (Fig. $1 \mathrm{e}$ ) is dominated by a NAO response locally over the North Atlantic (Fig. 5e), with a negative SST in the Gulf Stream forcing a negative NAO, the same sense as the response to NP1. This feature is robust to the lag and EOF truncation (not shown). The North Atlantic forcing on NAO has been discussed in previous observational and modeling studies, although substantial uncertainties remain (e.g., Frankignoul and Kestenare 2005; Peng et al. 2003).

North Atlantic forcing has a modest impact remotely on the atmosphere over the North Pacific and therefore affects the GEFA response to NP1. One notices that the weak local response to NP1 over the Aleutian low estimated using SSTs in the Pacific is enhanced after the expansion of SST modes into other oceans (Fig. 2c versus Fig. 5d, from 40 to $60 \mathrm{~m}$ ), such that the response over the Aleutian low becomes comparable with the remote response downstream on NAO. Further analyses suggest that this enhancement of local North Pacific response is caused mainly by the North Atlantic modes, especially NA3.

\section{Summary and discussion}

Here, the observed atmospheric response to major global SST modes is assessed in a unified framework.
The GEFA response confirms some robust responses in previous studies on tropical forcings, and it also identified some new responses to tropical and extratropical forcings. Most importantly, as a pilot study here, we demonstrate how the complex atmospheric response to multiple SST forcing can be studied systematically in a unified approach using GEFA.

It is found that the two dominant SST modes that affect the global atmosphere are the tropical Pacific ENSO mode and the tropical Indian Ocean monopole mode. The Pacific ENSO mode generates a significant baroclinic Rossby wave response locally over the tropical Pacific as well as robust remote responses in both hemispheres, dominated by the teleconnection wave trains of PNA and PSA. The Indian Ocean monopole, which is triggered largely by the Pacific ENSO and therefore represents the secondary effect of ENSO, forces a broad response throughout the tropics as well as significant remote responses in the extratropics, both characterized by a primarily zonally symmetric structure. Modest but statistically significant responses are also found generated by other SST modes. The North Pacific SST mode generates a warm SST-ridge response locally on the Aleutian low, as well as a significant downstream response on NAO through the Aleutian low-Icelantic low seesaw; the North Atlantic tripole mode and tropical Atlantic El Niño mode mainly affect the atmosphere locally over the North Atlantic and tropical Atlantic, respectively. In addition, there are also some modest responses to SST second EOFs (EOF2; appendix C). Overall, the major features of the atmospheric response are consistent with previous studies, especially for the tropical forcing, where consistent results have been obtained in both the observation and modeling. The modest response to midlatitude oceanic forcing identified here provides a useful benchmark for further studies in the observation and model. These modest responses to the slow oceanic variability in the extratropics, although they may not be important for short-term climate variability, could be critical for longterm climate variability at decadal and longer time scales (Liu et al. 2007)..$^{5}$

It should be pointed out that our study of the response sensitivity to different SST variability modes is important.

\footnotetext{
${ }^{5}$ Complementary to the point significance discussed earlier, we also performed a simple field significance test. The field significance of the GEFA response to a SST mode is tested first by projecting the atmospheric field onto this GEFA response pattern. The projection time series is then randomly scrambled for 1000 times to perform Monte Carlo test against the forcing mode using EFA. With this test, all the global response fields to the leading SST EOFs pass the significance of $95 \%$.
} 
For example, although the Indian Ocean SST (TI1) tends to follow El Niño by a few months (Klein et al. 1999; Yang et al. 2007), there are times when the two are of opposite signs and are accompanied by atmospheric responses significantly different from the combined response to TP1 and TI1 (Fig. 2a), as in 1998, when a warm Indian Ocean was accompanied by a cold equatorial Pacific (Hoerling and Kumar 2003; Lau et al. 2006). In these periods, the global atmospheric responses can differ significantly from those in the periods when SSTs in the Indian and Pacific Oceans are of the same sign. It should be further noted that this separate response study is useful even for those SST modes of small variance in the observed SST variability. This is because the monthly SST EOF modes reflect the dominant variability at seasonal to interannual time scales, with the Pacific El Niño mode of the overwhelming magnitude, and in turn atmospheric response over the globe. For climate variability and climate change of longer time scales, such as decadal variability and secular global warming scenarios, other SST modes, such as the Indian Ocean monopole mode TI1 (for the global response) and the North Pacific mode NP1 (for northern extratropical response), may become important if they have larger projections from the SST anomalies. These modes could therefore play a more important role than observed for seasonal to interannual variability. Furthermore, the impacts of many modes, although unimportant for global-scale responses, are important for specific regional climates.

Most significant here is the demonstration of the utility of GEFA as a systematic method to study the influence of ocean on large-scale climate. This approach can be used without a priori knowledge of the importance of the multiple forcings. This is in contrast to most past studies, which either use some types of simple univariate approaches, usually with a priori assumptions on remote forcing (appendixes A and B), or are limited to a single ocean basin. The GEFA approach can also be applied to a control simulation of a coupled model to evaluate the model atmospheric response with trivial computation cost relative to ensemble simulations. Furthermore, the GEFA approach can potentially include other surface forcings, notably land surface forcing (e.g., Z. Liu et al. 2006) and sea ice forcing, to provide a truly comprehensive feedback assessment of largescale atmospheric response to global surface forcing.

Some comments will be made on GEFA so that readers can better evaluate the limitation and utility of GEFA. First, GEFA response only gives the first-order linear approximation of the feedback response, because GEFA, as in most conventional statistical methods, assumes a linear response on a stationary process. There have been studies that the atmospheric response exhibit some nonlinearity to the SST variability in the tropics (Hoerling et al. 1997) and extratropics (Kushnir et al. 2002, and references therein). This nonlinear component of the response would require further studies using nonlinear statistical methods. It should be noted that the linearity on GEFA is required only on the atmospheric response to SST, rather than on the SST variability itself. Therefore, our GEFA estimate is not affected by the nonlinearity of the SST variability, such as in the tropical Pacific (Hannachi et al. 2003; Burgers and Stephenson 1999) and the Indian (Hannachi and Dommenget 2009) Oceans. Second, GEFA appears like a multiple regression. Indeed, the GEFA estimate of feedback matrix $\mathbf{B}_{z \mathbf{y}}(\tau)$ is related to two multiple regression matrices as

$$
\mathbf{R}_{z \mathbf{y}}(\tau)=\mathbf{B}_{z \mathbf{y}}(\tau) \boldsymbol{\Gamma}_{\mathbf{y y}}(\tau)
$$

where $\mathbf{R}_{x \mathbf{y}}(\tau)=\mathbf{C}_{x \mathbf{y}}(\tau) \mathbf{C}_{\mathbf{y y}}^{-1}(0)$ is the regression matrix of the prediction equation

$$
z(t)=\mathbf{R}_{z \mathbf{y}}(\tau) \mathbf{y}(t-\tau)+\varepsilon(t),
$$

and $\boldsymbol{\Gamma}_{\mathbf{y y}}(\tau)=\mathbf{C}_{\mathbf{y y}}(\tau) \mathbf{C}_{\mathbf{y y}}^{-1}(0)$ is the autocorrelation matrix of SST (see also appendix B of LWY08). In spite of its similar appearance to the multiple regression in the prediction Eq. (5.2), GEFA response represents the instantaneous atmospheric response in the equilibrium response (2.1). Given the clear physical meaning of GEFA, the prediction matrix $\mathbf{R}$ can be interpreted in (5.1) as the instantaneous GEFA response $\mathbf{B}$ decaying in response to the persistence of the SST variability $\boldsymbol{\Gamma}$. Third, the GEFA estimate is independent of the normality of the atmospheric variability. Indeed, the key condition for GEFA is independence of the prior SST variability (beyond the decorrelation time of $n$ ) and the atmospheric internal variability $n(t)$; that is, $C_{n \mathbf{y}}(\tau)=$ $\langle n(t), \mathbf{y}(t-\tau)\rangle=0$, as seen in the derivation of (2.2). This condition can be satisfied regardless of the normality of the SST variability and atmospheric variability. This is in contrast to some other methods, such as linear inverse modeling (LIM), which requires the normality of the atmospheric variability in deriving its maximum likelihood solution (Penland and Sardeshmukh 1995; see appendix B of LWY08 for the relation between GEFA and LIM).

Much work remains to be done to further understand the observed oceanic feedback on the global atmosphere. First of all, to better understand the atmospheric response, GEFA response needs to be extended to the other climate variables, including thermal and momentum (vorticity) forcings, and to the seasonality of the feedback. Response and mechanisms for specific regions will also need to be studied much more carefully. Finally, 
dynamic assessment with ensemble model simulation will need to be performed in the context of a GCM to complement the GEFA assessment. This dynamic assessment serves two purposes: it will shed light on the mechanism of the feedback response and it will serve as a further validation of the GEFA method, which is valid under the assumptions of linearity and quasi-equilibrium response. Preliminary studies with dynamic assessment in coupled GCMs have shown promising results for oceanatmosphere feedback (Liu and Wu 2004; Liu et al. 2007; Kwon and Deser 2007) and land-atmosphere feedback (Notaro and Liu 2007; Notaro et al. 2008) and have provided some support for the statistical assessment based on EFA. Similar studies need to be extended to the comparison of GEFA assessments with dynamic assessment, as suggested in LWY08 and LW08. This direct comparison between dynamic and statistical assessment is another advantage of GEFA. In comparison, many statistical methods involve multiple covariance and regressions that are not straightforward to test with dynamic experiments.

Finally, it is worth pointing out that the choice of regional SST EOFs as the spatial base is somewhat arbitrary, and the results may be modified if difference bases are used. For example, the tropical Indo-Pacific can also be separated into the eastern equatorial Pacific and the combined Indian Ocean-western Pacific warm pool regions (Lau et al. 2005; 2006), instead of the Indian and Pacific Oceans here. Ultimately, it depends on the purpose of the study. The important thing here is that GEFA can provide a flexible and systematic approach to assess the feedback of multiple surface forcings on the atmosphere in the observation.

Acknowledgments. We thank Drs. G. Branstator, M. Newman, P. Sardeshmukh, C. Penland, E. DeWeaver, and N.-C. Lau for helpful discussion. We thank Ms. F. Y. Wang for some calculations in the revision stage of work. We also thank two anonymous reviewers for helpful comments. This work is supported by DOE and NSF with Grants NSFC40830106 and NSFC40676010. Support from the Institut Universitaire de France is also acknowledged.

\section{APPENDIX A}

\section{GEFA and Residual EFA}

Most previous studies of boundary forcing on the atmosphere have been done after the filtering the influence of a dominant remote forcing such as the ENSO forcing. In this intuitive residual approach, a simple (univariate) regression is used to assess the forcing- response relationship for variables from which the impact of a remote forcing has been regressed out. ${ }^{6}$ Here, we show that, in the simplest setting of one response and two forcings, the residual approach is equivalent to the GEFA assessment if the lags for the regression filtering are chosen properly.

Assume the atmospheric response, local oceanic forcing, and remote oceanic forcing represented by $x, y$, and $z$, respectively. Assume the true response is a quasiequilibrium response,

$$
x(t)=r_{y} y(t)+r_{z} z(t)+n(t),
$$

where $r_{y}$ and $r_{z}$ are the true feedback parameters to the local forcing $y$ and remote forcing $z$, respectively, and $n$ is the internal variability noise. Following the GEFA approach, multiply $y$ and $z$ onto (A.1) with positive lags $u>0$ and $v>0$, respectively, such that $y$ and $z$ lead $n$ and therefore the lagged covariance $C_{n y}(u)=C_{n z}(v)=0$; we have

$$
\begin{aligned}
& C_{x y}(u)=r_{y} C_{y y}(u)+r_{z} C_{z y}(u) \\
& C_{x z}(v)=r_{y} C_{y z}(v)+r_{z} C_{z z}(v)
\end{aligned} .
$$

The local response $r_{y}$ can be estimated by solving the two equations of (A.2) simultaneously, as in GEFA, as an estimator of

$$
\hat{r}_{y}=\frac{C_{x y}(u) C_{z z}(v)-C_{x z}(v) C_{z y}(u)}{C_{y y}(u) C_{z z}(v)-C_{y z}(v) C_{z y}(u)} .
$$

This local GEFA response can also be derived using the residual approach in combination with EFA, with the lags of the regression filtering properly chosen. Define the residual response and residual local forcing as those after filtering of the remote forcing $z$ as

$$
x^{\prime}=x-\frac{C_{x z}(i)}{C_{z z C}(i)} z \quad \text { and } \quad y^{\prime}=y-\frac{C_{y z}(j)}{C_{z z}(j)} z,
$$

respectively, where $i \geq 0$ and $j \geq 0$ are two lags for regression filtering. The feedback response for the residual can now be assumed as

$$
x^{\prime}(t)=r_{y^{\prime}}^{\prime} y^{\prime}(t)+m(t),
$$

where $r_{y^{\prime}}^{\prime}$ is a new feedback parameter for the residual variability. Using EFA with a lag $k>0$ for assessment such that $y^{\prime}$ leads $x^{\prime}$, we have $C_{m y^{\prime}}(k)=0$. Then, noticing (A.4), the EFA feedback between the residual response and residual local forcing is derived as

\footnotetext{
${ }^{6}$ This residual approach can be shown to be similar to the partial correlation approach.
} 
a) REFA Z250 Rsp to TP1, $\sigma(\operatorname{TP} 1)=0.42^{\circ} \mathrm{C}$

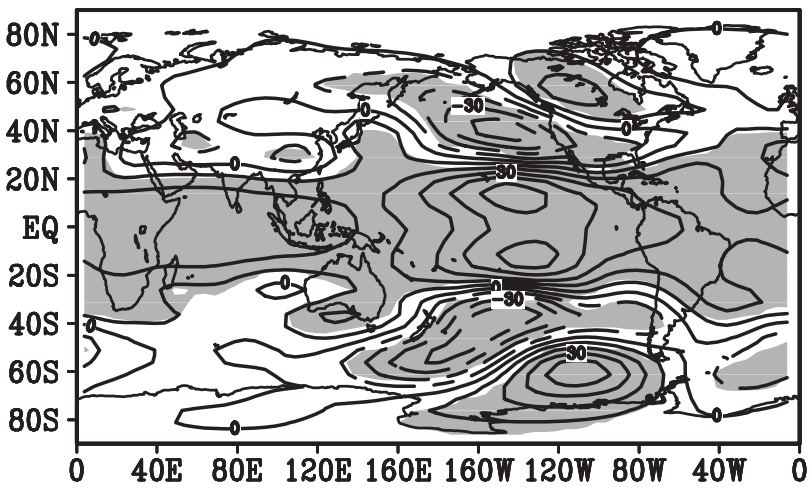

c) REFA Z850 Rsp to TP1, $\sigma(\mathrm{TP} 1)=0.42^{\circ} \mathrm{C}$

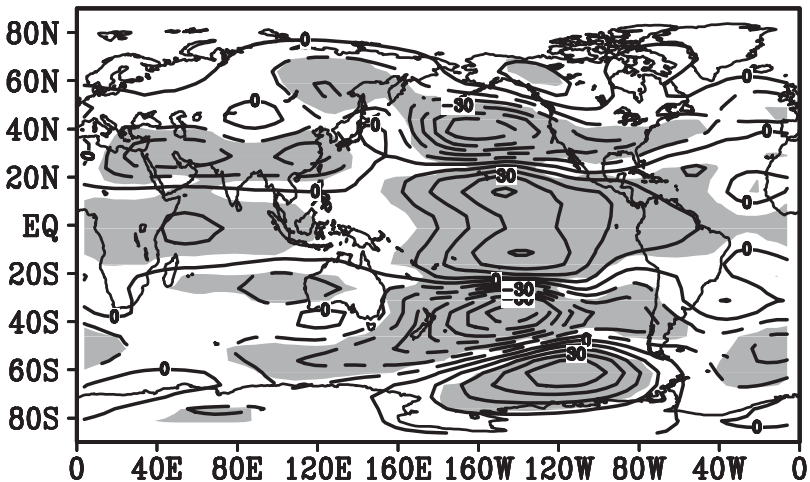

b) REFA Z250 Rsp to NP1, $\sigma(\mathrm{NP} 1)=0.26^{\circ} \mathrm{C}$

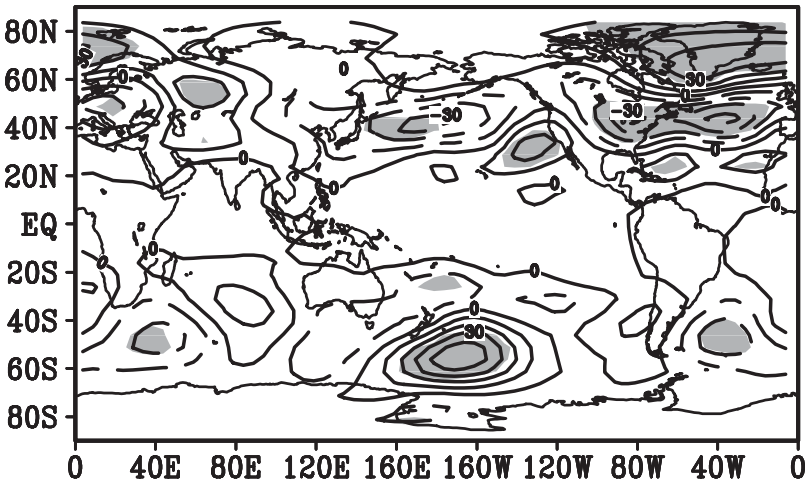

d) REFA Z850 Rsp to TI1, $\sigma(\mathrm{TI} 1)=0.23^{\circ} \mathrm{C}$

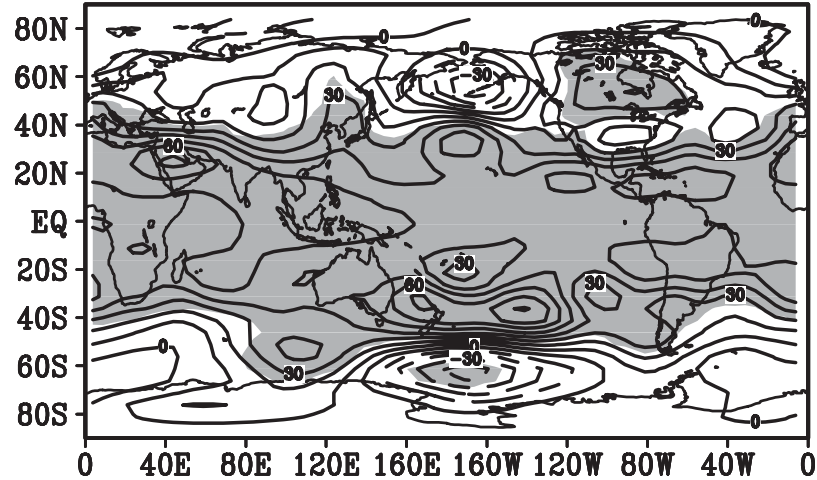

FIG. B1. The residual EFA response sensitivity of Z250 assessed following appendix A. (a) EFA response to TP1 after filtering the influence of NP1; (b) EFA response to NP1 after filtering the influence of TP1; (c) EFA response to TP1 after filtering the influence of TI1; and (d) EFA response to TI1 after filtering the influence of TP1 (solid lines for positive and dashed lines for negative; $\mathrm{CI}=10 \mathrm{~m}{ }^{\circ} \mathrm{C}^{-1}$, with $90 \%$ significance shaded).

$$
\hat{r}_{y^{\prime}}^{\prime}=\frac{C_{x^{\prime} y^{\prime}}(k)}{C_{y^{\prime} y^{\prime}}(k)}=\frac{C_{x y}(k)-\frac{C_{x z}(i)}{C_{z z}(i)} C_{z y}(k)-\frac{C_{y z}(j)}{C_{z z}(j)} C_{x z}(k)+\frac{C_{x z}(i)}{C_{z z}(i)} \frac{C_{y z}(j)}{C_{z z}(j)} C_{z z}(k)}{C_{y y}(k)-\frac{C_{y z}(j)}{C_{z z}(j)} C_{z y}(k)-\frac{C_{y z}(j)}{C_{z z}(j)} C_{y z}(k)+\frac{C_{y z}(j)}{C_{z z}(j)} \frac{C_{y z}(j)}{C_{z z}(j)} C_{z z}(k)} .
$$

In general, the residual EFA feedback $\hat{r}_{y^{\prime}}$ differs from the true feedback $r_{y}$. However, if the two lags are chosen as $i=j=k$, then (A.6) recovers the true feedback in (A.3) (with $u=v=i=j=k>0$ ) as

$$
\hat{r}_{y^{\prime}}^{\prime}=\frac{C_{x y}-\frac{C_{x z}}{C_{z z}} C_{z y}}{C_{y y}-\frac{C_{y z}}{C_{z z}} C_{z y}}=\hat{r}_{y}
$$

Thus, to ensure the correct assessment in the residual approach, in principle, it is necessary to use a nonzero lag of a common value for the two filtering $(i, j)$ and the assessment $(k)$. The nonzero lag is necessary to ensure the absence of covariance between the forcing and the internal variability in the EFA assessment $(k$; Frankignoul et al. 1998), whereas the common lag ensures the correct recovery of the feedback parameter as shown in (A.7).

Overall, the residual approach provides a convenient method for filtering a dominant remote forcing that is known a priori. However, the residual approach, even though only using univariate regressions, may not reduce the sampling error, because the variance of the residual forcing $y^{\prime}$ and in turn its autocovariance is reduced the same way as in the GEFA forcing covariance matrix. Furthermore, the residual approach is practical only if there is a single major external forcing and this forcing is known a priori. 
GEFA Z250 Rsp

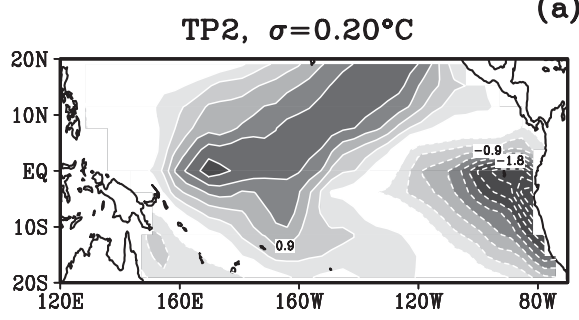

(a)

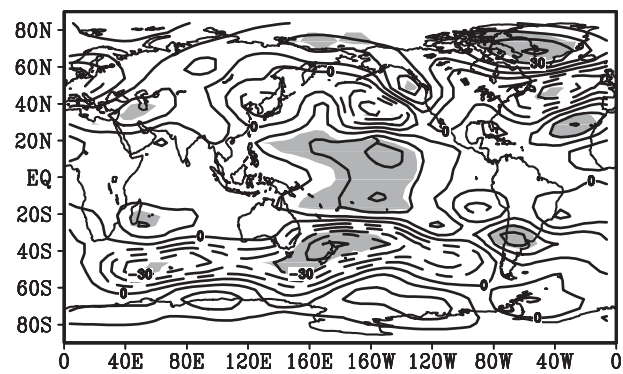

(b)
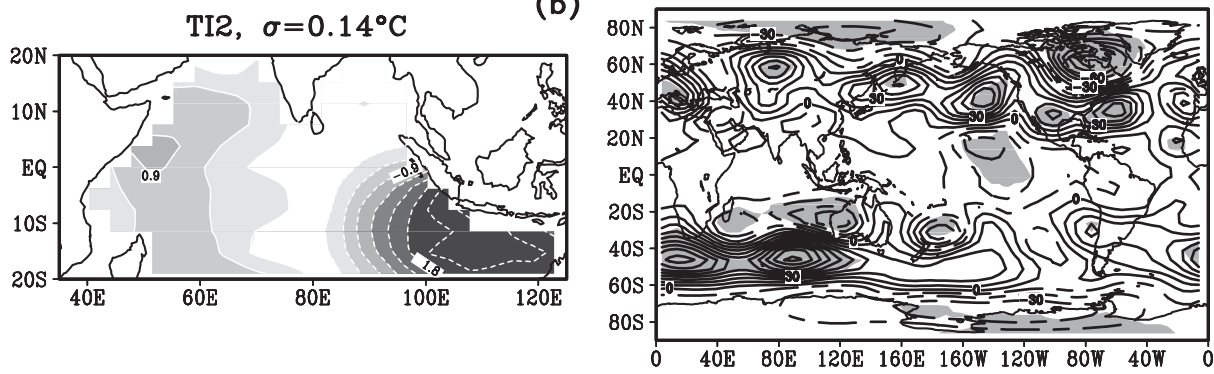

TA2, $\sigma=0.23^{\circ} \mathrm{C}$

(c)
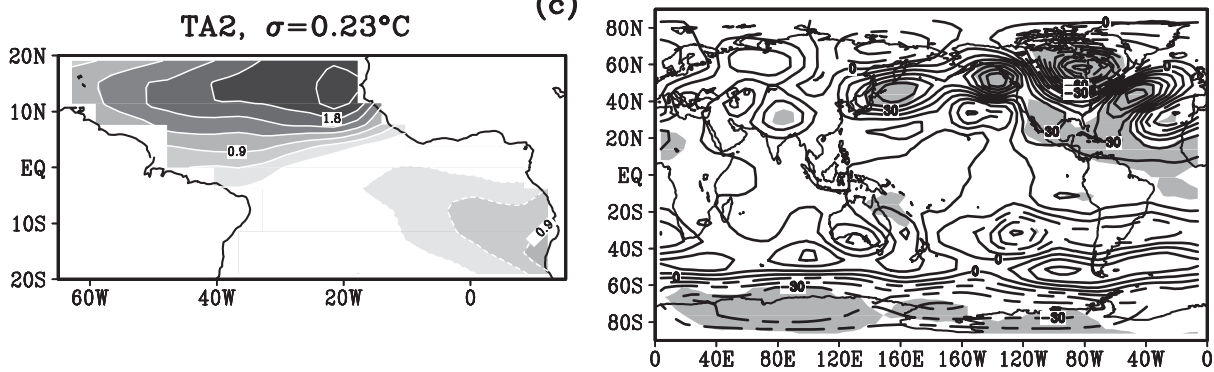

(d)
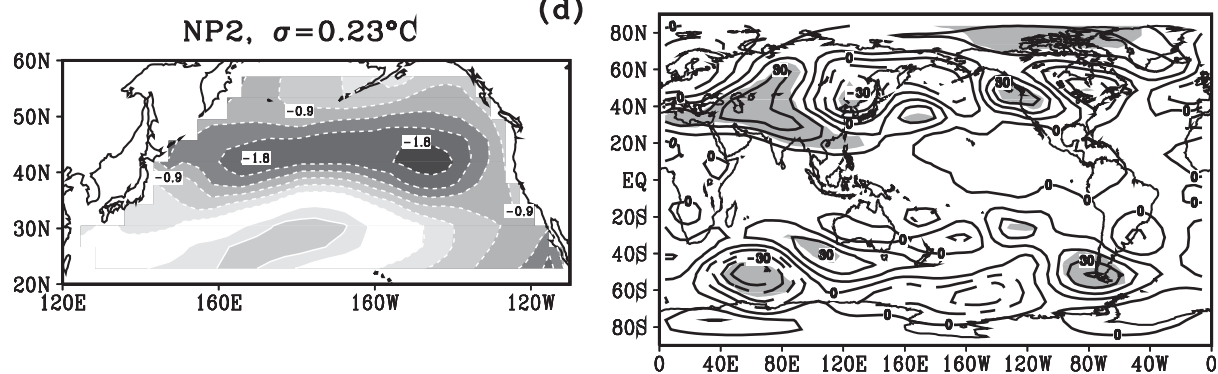

(e)
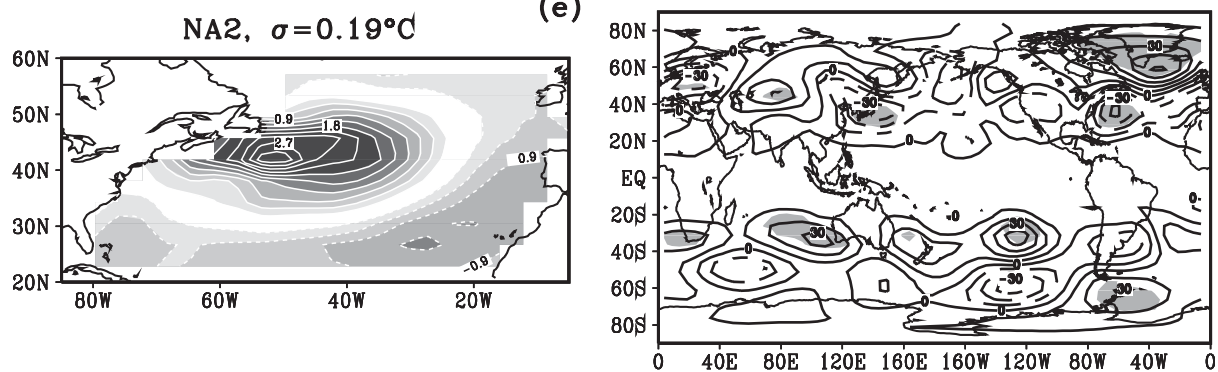

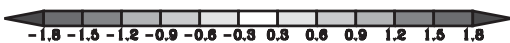

FIG. C1. (left) EOF2 and (right) the corresponding GEFA response sensitivity on Z250 to (a) TP2, (b) TI2, (c) TA2, (d) NP2, and (e) NA2 (solid lines for positive and dashed lines for negative; CI = $0.3^{\circ} \mathrm{C}$ for SST and $\mathrm{CI}=10 \mathrm{~m}^{\circ} \mathrm{C}^{-1}$ for $\mathrm{Z} 250$, with $90 \%$ significance level shaded for $\mathrm{Z} 250$ ). The magnitude of the spatial pattern of SST EOF is normalized with a standard deviation of $1^{\circ} \mathrm{C}$. 


\section{APPENDIX B}

\section{Assessing Observed Atmospheric Response to SST Forcing with Residual EFA}

Here, we apply the residual EFA approach to assess the response of Z250 to major SST modes and compare them with the total responses and GEFA responses discussed earlier. First, we assess the residual response to TP1 by filtering out NP1 (Fig. B1a). The resulting EFA response is virtually the same as the total response to TP1 (Fig. 4a) or the GEFA response to TP1 using SSTs in the tropical-North Pacific SSTs (Fig. 2a). This is reasonable, because NP1 has little contribution to the TP1 response, as discussed in section 3 . In contrast, the residual response to NP1 after filtering TP1 (Fig. B1b) differs significantly from the total response to NP1 (Fig. 4b), but it resembles the GEFA response to NP1, especially the downstream response on NAO with SST forcing in the tropical-North Pacific (Fig. 2c) or more oceans (Fig. 5d). Now, the residual response to NP1 is weak locally over the Aleutian low because of the contributions of the North Atlantic SST, as discussed at the end of section 4. Furthermore, if the residual assessment is applied to the response to TP1 but with the filtering on the TI1 (Fig. B1c), the response to TP1 differs significantly from the total response (Fig. 4a) but closely resembles the GEFA response with expanded SSTs in the tropical Indian Ocean (Fig. 5a). Finally, if the residual approach is applied to the response to TI1 with the filtering of TP1, the response (Fig. B1d) differs significantly from the total response to TI1 (Fig. 4c) but resembles the GEFA response to TI1 with all tropical SSTs included (Fig. 5b). Therefore, the residual approach is feasible when the major external forcing is known correctly a priori. In contrast, GEFA provides a comprehensive assessment as long as sufficient forcings are included.

\section{APPENDIX C}

\section{GEFA Response to EOF2}

For completeness, we briefly discuss the GEFA response to EOF2s. Figure $\mathrm{C} 1$ shows the second EOFs of SST anomaly for the five ocean basins and their corresponding GEFA response sensitivity. Overall, the responses to EOF2s are much weaker than the responses to TP1 and TI1 (Figs. 5a,b) but are of comparable magnitude (in response sensitivity) and statistical significance with the responses to other EOF1s (Figs. 5c-e).

The TP2 consists of a dipole resembling the Pacific meridional mode (PMM; Chiang and Vimont 2004). The
TP2 forces a high Z250 anomaly over the warm SST in the central-western tropical Pacific (Fig. C1a), consistent with the Gill (1980) dynamics. This response pattern is also consistent with the precipitation anomaly associated with the PMM as analyzed in Chiang and Vimont (2004), which is done with the TP1 mode first removed as in the classical residual approach (appendixes A and B).

The TI2 (Fig. C1b) is the Indian Ocean dipole (IOD) mode (Saji et al. 1999). TI2 does not seem to generate a significant response locally in the Asian monsoon region (Fig. C1b), which may appear to be inconsistent with some previous suggestions (Saji et al. 1999; Ashok et al. 2001). Partly, this discrepancy may be caused by the year-round response here, which accounts for neither the strong seasonality of the monsoon circulation nor the strong seasonality of the IOD itself, which is the most prominent only in the fall. The IOD seems to force some significant response remotely over the southern Indian Ocean region, including Western Australia. This appears to be consistent with a previous analysis on the role of IOD in Australia winter rainfall (Ashok et al. 2003). The IOD also appears to exert a significant remote impact on the NAO region.

The tropical Atlantic dipole mode TA2 has its loading mainly over the tropical North Atlantic (Fig. C1c). TA2 seems to excite a significant response mainly over the North Atlantic region (Fig. C1c). This remote response appears to be consistent with some modeling studies, suggesting an important role of tropical Atlantic on NAO through the atmospheric teleconnection and the subsequent ocean-atmosphere interaction in the North Atlantic (e.g., Sutton et al. 2001; Drévillon et al. 2003; Peng et al. 2005).

The NP2 mode is dominated by a basin-wide anomaly in the subpolar North Pacific (Fig. C1d). Different from the response to NP1, which is dominated by a downstream response over the North Atlantic (Fig. 5d), NP2 seems to generate a strong remote response upstream over the midlatitude Eurasian continent (Fig. C1d). The NA2 mode exhibits a dipole structure between the North Atlantic Current region and the subtropical North Atlantic (Fig. C1e), and it influences the NAO (Fig. C1e), which is similar to the horseshoe SST anomaly influence on the NAO detected in early winter by Czaja and Frankignoul (2002).

\section{REFERENCES}

Alexander, M. A., I. Blade, M. Newman, J. R. Lanzante, N.-C. Lau, and J. D. Scott, 2002: The atmospheric bridge: The influence of ENSO teleconnections on air-sea interaction over the global oceans. J. Climate, 15, 2205-2231.

Allen, R., and Coauthors, 2001: Is there an Indian Ocean dipole, and is it independent of the El Niño-Southern Oscillation? 
CLIVAR Exchanges, No. 21, International CLIVAR Project Office, Southampton, United Kingdom, 18-22.

Ashok, K., Z. Guan, and T. Yamagata, 2001: Impact of the Indian Ocean dipole on the relationship between the Indian monsoon rainfall and ENSO. Geophys. Res. Lett., 28, 4499-4502.

,$- \ldots$, and — 2003: Influence of the Indian Ocean dipole on the Australian winter rainfall. Geophys. Res. Lett., 30, 1821, doi:10.1029/2003GL017926.

Barsugli, J. J., and P. D. Sardeshmukh, 2002: Global atmospheric sensitivity to tropical SST anomalies throughout the IndoPacific basin. J. Climate, 15, 3427-3442.

Bjerknes, J., 1966: A possible response of the atmospheric Hadley circulation to equatorial anomalies of ocean temperatures. Tellus, 18, 820-829.

—, 1969: Atmospheric teleconnections from the equatorial Pacific. Mon. Wea. Rev., 97, 163-172.

Burgers, G., and D. B. Stephenson, 1999: The "normality" of El Niño. Geophys. Res. Lett., 26, 1027-1030.

Chiang, J. C. H., and A. Sobel, 2002: Tropical tropospheric temperature variations caused by ENSO and their influence on the remote tropical climate. J. Climate, 15, 2616-2631.

— meridional modes of tropical atmosphere-ocean variability. $J$. Climate, 17, 4143-4158.

Czaja, A., and C. Frankignoul, 2002: Observed impact of North Atlantic SST anomalies on the North Atlantic Oscillation. J. Climate, 15, 606-623.

Drévillon, M., C. Cassou, and L. Terray, 2003: Model study of the North Atlantic region atmospheric response to autumn tropical Atlantic sea-surface-temperature anomalies. Quart. J. Roy. Meteor. Soc., 129, 2591-2611.

Ferreira, D., and C. Frankignoul, 2005: The transient atmospheric response to midlatitude SST anomalies. J. Climate, 18, 10491067.

Frankignoul, C., and E. Kestenare, 2005: Observed Atlantic SST anomaly impact on the NAO: An update. J. Climate, 18, 4089-4094.

— SST anomalies on the atmospheric circulation. J. Climate, 20, 592-606.

— A. Czaja, and B. L'Heveder, 1998: Air-sea feedback in the North Atlantic and surface boundary conditions for ocean models. J. Climate, 11, 2310-2324.

Gill, A. E., 1980: Some simple solutions for heat-induced tropical circulation. Quart. J. Roy. Meteor. Soc., 106, 447-462.

Gritsun, A., and G. Branstator, 2007: Climate response using a three-dimensional operator based on the fluctuation-dissipation theorem. J. Atmos. Sci., 64, 2558-2575.

Hannachi, A., and D. Dommenget, 2009: Is the Indian Ocean SST variability a homogeneous diffusion process? Climate Dyn., 33, 535-547, doi:10.1007/s00382-008-0512-5.

— D. B. Stephenson, and K. R. Sperber, 2003: Probability-based methods for quantifying nonlinearity in ENSO. Climate Dyn., 20, 241-256.

Hodson, D. L. R., R. T. Sutton, C. Cassou, N. Keenlyside, Y. Okumura, and T. Zhou, 2010: Climate impacts of recent multidecadal changes in Atlantic Ocean sea surface temperature: A multimodel comparison. Climate Dyn., in press.

Hoerling, M. P., and A. Kumar, 2003: The perfect ocean for drought. Science, 299, 691-694.

— — - and M. Zhong, 1997: El Niño, La Niña, and the nonlinearity of their teleconnections. J. Climate, 10, 1768-1786.
— J. W. Hurrell, T. Xu, G. T. Bates, and A. S. Phillips, 2004: Twentieth century North Atlantic climate change. Part II: Understanding the effect of Indian Ocean warming. Climate Dyn., 23, 391-405.

Honda, M., H. Nakamura, J. Ukita, I. Kousaka, and K. Takeuchi, 2001: Interannual seesaw between the Aleutian and Icelandic lows. Part I: Seasonal dependence and life cycle. J. Climate, 14, 1029-1042.

_- S. Yamane, and H. Nakamura, 2005: Impacts of the AleutianIcelandic seesaw on surface climate during the twentieth century. J. Climate, 18, 2793-2802.

Hoskins, B. J., and D. J. Karoly, 1981: The steady linear response of a spherical atmosphere to thermal and orographic forcing. J. Atmos. Sci., 38, 1179-1196.

Houghton, R. W., and Y. M. Tourre, 1992: Characteristics of lowfrequency sea surface temperature fluctuations in the tropical Atlantic. J. Climate, 5, 765-772.

Klein, S. A., B. J. Soden, and N.-C. Lau, 1999: Remote sea surface temperature variations during ENSO: Evidence for a tropical atmospheric bridge. J. Climate, 12, 917-932.

Kumar, A., and M. P. Hoerling, 2003: The nature and causes for the delayed atmospheric response to El Niño. J. Climate, 16, 13911403.

Kushnir, Y., W. A. Robinson, I. Blade, N. M. J. Hall, S. Peng, and R. Sutton, 2002: Atmospheric GCM response to extratropical SST anomalies: Synthesis and evaluation. J. Climate, 15, 22332256.

Kwon, Y.-O., and C. Deser, 2007: North Pacific decadal variability in the Community Climate System Model version 2. J. Climate, 20, 2416-2433.

Lau, N.-C., A. Leetmaa, M. J. Nath, and H.-L. Wang, 2005: Influences of ENSO-induced Indo-western Pacific SST anomalies on extratropical atmospheric variability during the boreal summer. J. Climate, 18, 2922-2942.

,-- , and — 2006: Attribution of atmospheric variations in the 1997-2003 period to SST anomalies in the Pacific and Indian Ocean basins. J. Climate, 19, 3607-3628.

Liu, Q., N. Wen, and Z. Liu, 2006: An observational study of the impact of the North Pacific SST on the atmosphere. Geophys. Res. Lett., 33, L18611, doi:10.1029/2006GL026082.

Liu, Z., and L. Wu, 2004: Atmospheric response to North Pacific SST: The role of ocean-atmosphere coupling. J. Climate, 17, 1859-1882.

— , and M. Alexander, 2007: Atmospheric bridge, oceanic tunnel, and global climatic teleconnections. Rev. Geophys., 45, RG2005, doi:10.1029/2005RG000172.

— feedback. Part II: EFA-SVD and optimal feedback modes. J. Climate, 21, 5402-5416.

—, M. Notaro, J. Kutzbach, and N. Liu, 2006: Assessing global vegetation-climate feedbacks from the observation. J. Climate, 19, 787-814.

_, Y. Liu, L. Wu, and R. Jacob, 2007: Seasonal and long-term atmospheric responses to reemerging North Pacific Ocean variability: A combined dynamical and statistical assessment. J. Climate, 20, 955-980.

- N. Wen, and Y. Liu, 2008: On the assessment of nonlocal climate feedback. Part I: The generalized equilibrium feedback analysis. J. Climate, 21, 134-148.

Newman, M., G. Compo, and M. Alexander, 2003: ENSO-forced variability of the Pacific decadal oscillation. J. Climate, 16, 3853-3857. 
Notaro, M., and Z. Liu, 2007: Potential impact of Eurasian boreal forest on North Pacific climate variability. J. Climate, 20,981-992.

—_, Y. Wang, Z. Liu, R. Gallimore, and S. Levis, 2008: Combined statistical and dynamical assessment of the simulated vegetation-rainfall interactions in North Africa during the mid-Holocene. Global Change Biol., 14, 347-368.

Palmer, T., and Z. Sun, 1985: A modeling and observational study of the relationship between sea surface temperature in the northwest Atlantic and the atmospheric general circulation. Quart. J. Roy. Meteor. Soc., 111, 947-975.

Peng, S., and J. S. Whitaker, 1999: Mechanisms determining the atmospheric response to midlatitude SST anomalies. $J$. Climate, 12, 1393-1408.

— W. A. Robinson, and M. P. Hoerling, 1997: The modeled atmospheric response to midlatitude SST anomalies and its dependence on background circulation states. J. Climate, 10, 971-987.

_ — - a a a S. Li, 2003: Mechanism for the NAO response to the North Atlantic SST tripole. J. Climate, 16, 1987-2004.

,,--- , and M. P. Hoerling, 2005: Tropical Atlantic SST forcing of coupled North Atlantic seasonal responses. J. Climate, 18, 480-496.

Penland, C., and P. D. Sardeshmukh, 1995: The optimal growth of tropical sea surface temperature anomalies. J. Climate, 8 , 1999-2024.

Robertson, A. W., and C. R. Mechoso, 2003: Circulation regimes and low-frequency oscillations in the South Pacific sector Mon. Wea. Rev., 131, 1566-1576.

Saji, N. H., B. N. Goswami, P. N. Vinayachandran, and T. Yamagata, 1999: A dipole mode in the tropical Indian Ocean. Nature, 401, 360-363.

SanchezGomez, E., C. Cassou, D. L. R. Hodson, N. Keenlyside, Y. Okumura, and T. Zhou, 2008: North Atlantic weather regimes response to Indian-western Pacific Ocean warming: A multi-model study. Geophys. Res. Lett., 35, L15706, doi:10.1029/ 2008GL034345.
Seager, R., N. Harnik, Y. Kushnir, W. Robinson, and J. Miller, 2003: Mechanisms of hemispherically symmetric climate variability. J. Climate, 16, 2960-2978.

Sutton, R. T., and D. L. R. Hodson, 2003: The influence of the ocean on North Atlantic climate variability 1871-1999. J. Climate, 16, 3296-3313.

- W. A. Norton, and S. P. Jewson, 2001: The North Atlantic Oscillation-What role for the ocean? Atmos. Sci. Lett., 1, 89100, doi:10.1006/asle.2000.0021.

Thompson, D. W. J., S. Lee, and M. P. Baldwin, 2003: Atmospheric processes governing the Northern Hemisphere annual mode/ North Atlantic Oscillation. The North Atlantic Oscillation: Climatic Significance and Environmental Impact, Geophys. Monogr., Vol. 134, 81-112.

Trenberth, K., G. W. Branstator, D. Karoly, A. Kumar, N.-C. Lau, and C. Ropelewski, 1998: Progress during TOGA in understanding and modeling global teleconnections associated with tropical sea surface temperatures. J. Geophys. Res., 103, 14 29114324.

Wallace, J. M., and D. S. Gutzler, 1981: Teleconnections in the geopotential height field during the Northern Hemisphere winter. Mon. Wea. Rev., 109, 784-812.

Webster, P. J., and J. R. Holton, 1982: Cross-equatorial response to middle-latitude forcing in a zonally varying basic state. J. Atmos. Sci., 39, 722-733.

Wu, L., F. He, and Z. Liu, 2005: Coupled ocean-atmosphere response to north tropical Atlantic SST variability: Tropical Atlantic dipole and ENSO. Geophys. Res. Lett., 32, L21712, doi:10.1029/2005GL024222.

Yamagata, T., S. K. Behera, S. A. Rao, Z. Guan, K. Ashok, and H. N. Saji, 2003: Comments on "Dipoles, temperature gradients, and tropical climate anomalies." Bull. Amer. Meteor. Soc., 84, 1418-1422.

Yang, J., Q. Liu, S.-P. Xie, Z. Liu, and L. Wu, 2007: Impact of the Indian Ocean SST basin mode on the Asian summer monsoon. Geophys. Res. Lett., 34, L02708, doi:10.1029/2006GL028571. 